Check for updates

Cite this: RSC Adv., 2021, 11, 31621

\title{
New total synthesis and structure confirmation of putative (+)-hyacinthacine $\mathrm{C}_{3}$ and (+)-5-epi- hyacinthacine $\mathrm{C}_{3}^{\dagger}$
}

\author{
Livia Dikošová, ${ }^{a}$ Barbora Otočková, ${ }^{a}$ Tomáš Malatinský, ${ }^{a}$ Jana Doháňošová, \\ Mária Kopáčová, ${ }^{c}$ Anna Ďurinová, ${ }^{d}$ Lucie Smutná, ${ }^{d}$ František Trejtnar*d \\ and Róbert Fischer (D) *a
}

A unique synthesis of polyhydroxylated pyrrolizidine alkaloids, namely (+)-hyacinthacine $C_{3}$ and (+)-5-epihyacinthacine $\mathrm{C}_{3}$ is presented. The strategy relies on a 1,3-dipolar cycloaddition of an L-mannose derived nitrone, which owing to its great syn-stereoselectivity builds up the majority of the required stereocenters. The following key steps include Wittig olefination and iodine-mediated aminocyclisation, that provide two epimeric pyrrolizidines with the appropriate configuration. As a result, structure and steric arrangement of the first synthetically prepared (+)-hyacinthacine $C_{3}$ are proved to be correct, clearly confirming the inconsistency with the stereochemistry assigned to the natural sample. With respect to the previously proven glycosidase inhibitory activities, the antiproliferative effect of (+)-hyacinthacine $C_{3}$ and (+)-5-epi-hyacinthacine $C_{3}$ was evaluated using several cell line models.

Received 17th August 2021

Accepted 10th September 2021

DOI: $10.1039 / \mathrm{d} 1 \mathrm{ra06225e}$

rsc.li/rsc-advances

placenta $\alpha$-L-fucosidase $\left(\mathrm{IC}_{50}=17 \mu \mathrm{M}\right)$. Hyacinthacine $\mathrm{C}_{3}$ was

\section{Introduction}

Polyhydroxylated pyrrolizidine alkaloids are frequent candidates for the investigation of their potential antiviral properties and other medicinal applications such as treatment of diabetes, obesity, cancer, viral and bacterial infections. ${ }^{1}$ They exhibit powerful glycosidase inhibitory activities due to their structural similarity with the furanose ring found in the monosaccharides. ${ }^{2}$

Hyacinthacines are naturally occurring polyhydroxylated pyrrolizidine alkaloids which have been isolated from plants of the Hyacinthaceae family. So far, more than 20 compounds belonging to this group have been isolated and described. Among them, hyacinthacines $\mathrm{C}_{2}(\mathbf{1})$ and $\mathrm{C}_{3}(\mathbf{2 a})$ were isolated together with other hyacinthacines from the bulbs of Scilla socialis (Fig. 1). ${ }^{3}$ The glycosidase inhibitory studies revealed that hyacinthacine $\mathrm{C}_{2}$ exhibited a moderate inhibition of the human

${ }^{a}$ Institute of Organic Chemistry, Catalysis and Petrochemistry, Slovak University of Technology in Bratislava, Radlinského 9, 81237 Bratislava, Slovak Republic. E-mail: robert.fischer@stuba.sk

${ }^{b}$ Central Laboratories, Slovak University of Technology in Bratislava, Radlinského 9, 81237 Bratislava, Slovak Republic

'Institute of Chemistry, Slovak Academy of Sciences, Dúbravská cesta 9, 84538 Bratislava, Slovak Republic

${ }^{d}$ Charles University, Faculty of Pharmacy in Hradec Kralove, Heyrovskeho 1203, 50005 Hradec Kralove, Czech Republic. E-mail: trejtnarf@faf.cuni.cz

$\dagger$ Electronic supplementary information (ESI) available: Synthesis of isoxazolidine intermediate $6,{ }^{1} \mathrm{H}$ and ${ }^{13} \mathrm{C}$ NMR spectra of $\mathbf{2 a}, \mathbf{2 b}, \mathbf{4 - 1 0}, \mathbf{1 2 - 1 9}$, the comparison tables of the ${ }^{1} \mathrm{H}$ and ${ }^{13} \mathrm{C}$ NMR data between the synthetic (+)-hyacinthacine (2a) and the natural sample, NOESY spectra of 14, 15, 2a, 2b, evaluation of antiproliferative effect of $2 \mathbf{a}$ and $2 \mathbf{b}$. See DOI: 10.1039/d1ra06225e found to be a weak inhibitor of bovine liver $\beta$-galactosidase $\left(\mathrm{IC}_{50}\right.$ $=52 \mu \mathrm{M})$. Both alkaloids inhibited C. saccharolyticum $\beta$-glucosidase with $\mathrm{IC}_{50}$ values of 13 and $25 \mu \mathrm{M}$, respectively.

Hyacinthacines $\mathrm{C}_{2}$ and $\mathrm{C}_{3}$, along with their unnatural 5epimers, have been prepared synthetically only once. ${ }^{4}$ However, only the structure of $\mathbf{1}$ was identical with the natural sample indicating that the primarily assigned relative configuration of 2a could require a correction.

Due to the lack of absolute configuration information obtained from the X-ray structural analysis of hyacinthacines, there are currently many inaccuracies in their structures and configuration. In most cases, their structure and relative configuration have been determined only by $2 \mathrm{D}$ NMR
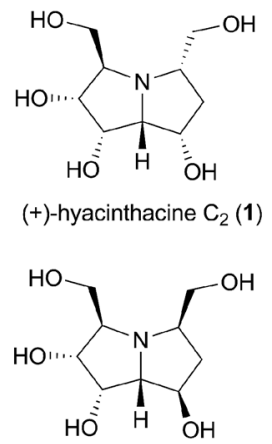

(+)-5-epi-hyacinthacine $\mathrm{C}_{3}(\mathbf{2 b})$ (+)-hyacinthacine $\mathrm{C}_{2}(1)$

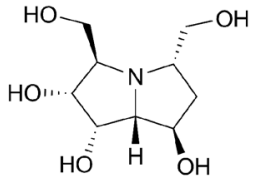

(+)-hyacinthacine $\mathrm{C}_{3}(\mathbf{2 a})$

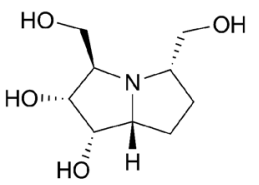

(+)-hyacinthacine $B_{2}(3)$
Fig. 1 Examples of polyhydroxylated 3,5-bis(hydroxymethyl)pyrrolizidine alkaloids. 
experiments, based on the $\mathrm{J}(\mathrm{HH})$ coupling constants and the observed NOEs. For this reason, efforts toward the total syntheses of this group of alkaloids, to confirm or refute their relative and absolute configuration, are still attractive. ${ }^{5}$

Our previous success with the synthesis of the unnatural enantiomer of $(+)$-hyacinthacine $\mathrm{B}_{2}(3)$, belonging to the class of structurally intriguing 3,5-bis(hydroxymethyl)pyrrolizidine alkaloids (Fig. 1), ${ }^{6}$ inspired us to prepare the (+)-hyacinthacine $\mathrm{C}_{3}$ (2a) and its C-5 epimer $\mathbf{2 b}$. Comparison of our results to the already reported data would bring definite clarity into the discussion about their structure, which would also create basis for their expected biological properties. Since it is well known that these compounds exhibit inherent glycosidase inhibitory activities, ${ }^{5}$ our aim was to evaluate the antiproliferative effects of the synthesized alkaloids. To the best of our knowledge, this would be for the first time when such polyhydroxylated pyrrolizidines would be tested against human cancer cell lines.

The essence of the new synthetic route is contained in three fundamental steps (Scheme 1), including highly syn-stereoselective 1,3-dipolar cycloaddition of L-mannose derived cyclic nitrone 7 which provides (3,3a-trans,3a,4-cis)-isoxazolidine exo-syn-6 ensuring the $1,7 \mathrm{a}$-cis, as well as 7,7a-trans configuration in the desired pyrrolizidine. The conversion of the dioxolane sidechain into a protected hydroxymethyl substituent (acidic hydrolysis, oxidative cleavage, reduction, silylation) and acidic hydrolysis of the carbonate is followed by a very straightforward extension of the isoxazolidine diol 5 backbone by Wittig olefination. The introduced alkene moiety in pyrrolidine derivative $\mathbf{4}$ is a vital part of the structure, as it serves in the iodine-mediated aminocyclisation reaction, that offers two C5-epimeric 6-iodo-pyrrolizidine structures. Their dehalogenation and final deprotection generates (+)-hyacinthacine $\mathrm{C}_{3}(\mathbf{2 a})$ and $(+)-5$ epi-hyacinthacine $\mathrm{C}_{3}(\mathbf{2 b})$.

\section{Results and discussion}

\section{Synthesis of isoxazolidine diol}

The essential building block of the presented synthesis, L- $^{-}$ mannose-derived nitrone 7 , was prepared by a slightly modified procedure described in the literature in total yield of $54 \%$ in six steps. ${ }^{7,8}$ Its highly syn-stereoslective 1,3-dipolar cycloaddition with vinylene carbonate resulted in a formation of cycloadduct exo-syn-6 as a major isomer (exo-syn-6 : exo-anti-6, 90 : 10 ratio based on ${ }^{1} \mathrm{H}$ NMR spectrum of the crude product) in $67 \%$ yield (ESI $\dagger) .{ }^{9}$ Prior to carbonate hydrolysis, we have decided to convert the acetonide side chain of 6 into a protected hydroxymethyl substituent (Scheme 2). The vicinal diol 8 was obtained in a 91\% yield by a selective acid-catalysed alcoholysis with $p$ TSA $\cdot \mathrm{H}_{2} \mathrm{O}$ in ethanol. The oxidative cleavage of the diol with sodium periodate followed by reduction of the obtained aldehyde with sodium borohydride led to formation of alcohol 9 in $80 \%$ over two steps. ${ }^{10}$ The reaction of 9 with TBDPSCl afforded the protected alcohol 10 in $92 \%$ yield. The desired isoxazolidine diol 5 was provided by a base-catalysed hydrolysis with $\mathrm{Et}_{3} \mathrm{~N}$ in aqueous methanol as a mixture of two undefined anomers in an anomeric ratio $90: 10$.

\section{Synthesis of the pyrrolidine intermediate via Wittig olefination}

With the starting diol 5 in hand, we were ready to examine the possibility of application of the Wittig olefination in the synthesis of pyrrolizidines. ${ }^{11}$ Accordingly, the isoxazolidine diol 5 was left to react with commercially available stable phosphorous ylide $\mathbf{1 1}$ at room temperature in dichloromethane for $48 \mathrm{~h}$ (Scheme 3) leading to the formation of $\alpha, \beta$-unsaturated ester 12 in very good $89 \%$ isolated yield as almost exclusively $(E)$ isomer with large coupling constant $J_{\mathrm{CH}=\mathrm{CH}}=15.5 \mathrm{~Hz}(E / Z$, $95: 5)$. The structure of the minor $(Z)$-isomer was predicted to be formed based on another double bond signals detected in ${ }^{1} \mathrm{H}$ NMR spectrum of the crude reaction mixture, however, the compound was never isolated in a pure form due to its low stability. It is noteworthy that no spontaneous intramolecular oxa-Michael addition of hydroxylamine nucleophile in $\mathbf{1 2}$ occurred, that would eventually lead to formation of new bicyclic isoxazolidine. Subsequently, ester 12 was reduced with DIBAL-H in anhydrous $\mathrm{CH}_{2} \mathrm{Cl}_{2}$ at $-20{ }^{\circ} \mathrm{C}$ to afford alkenol 13 in
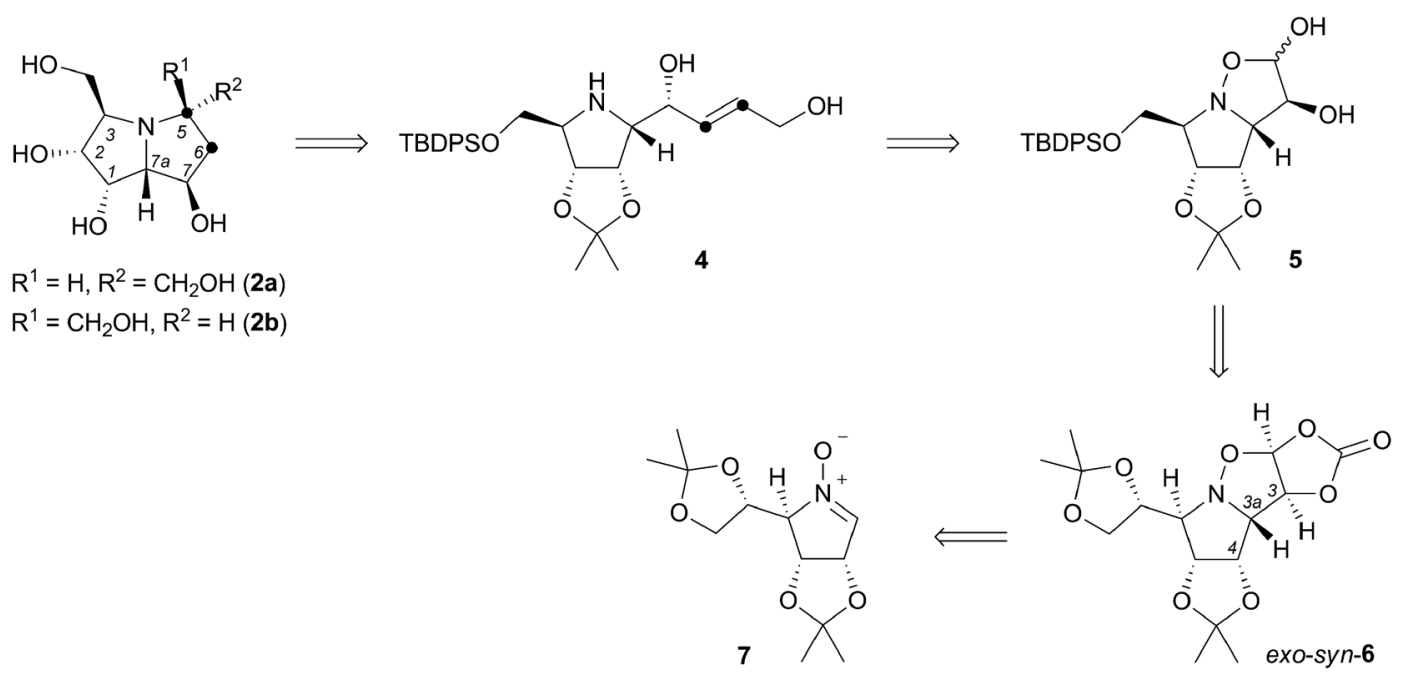

Scheme 1 Retrosynthesis of (+)-hyacinthacine $C_{3}(2 a)$ and (+)-5-epi-hyacinthacine $C_{3}(2 b)$ starting from L-mannose derived nitrone 7. 

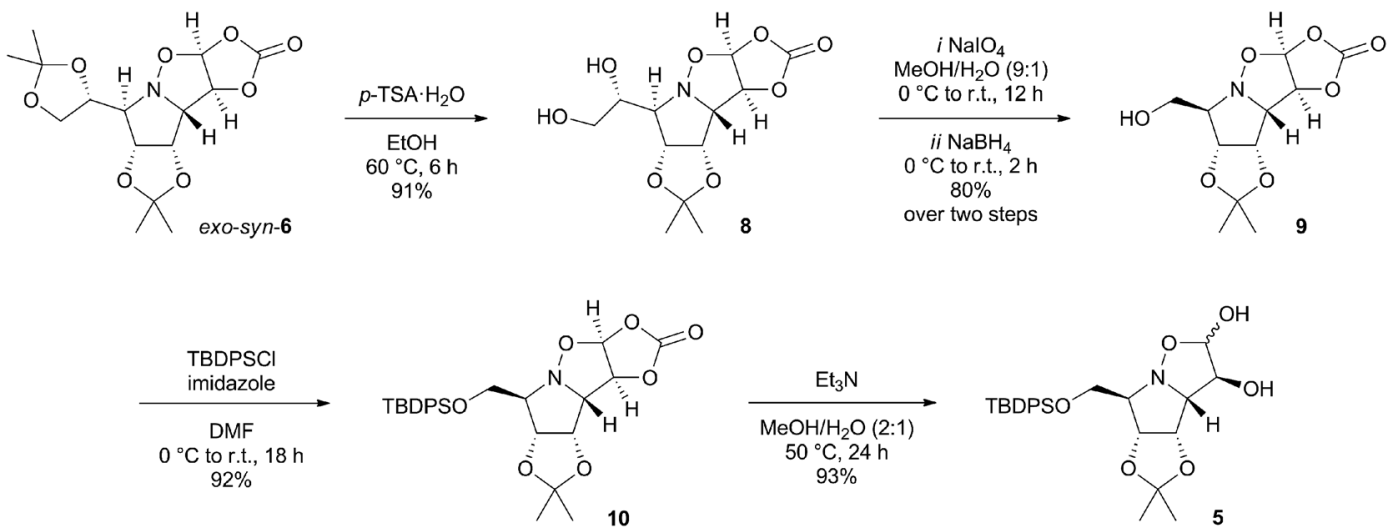

Scheme 2 Synthesis of isoxazolidine diol 5.<smiles>CC(C)OC[C@H]1[C@@H]2OC(C)(C)O[C@H]2[C@H]2[C@@H](O)[C@@H](O)ON12</smiles><smiles>CCOC(=O)C=[PbH]</smiles>

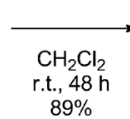<smiles>CCOC(=O)C=C[C@@H](O)[C@H]1[C@H]2OC(C)(C)O[C@H]2[C@H](COC(C)C)N1O</smiles>

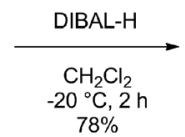<smiles>CC(C)OC[C@H]1[C@@H]2OC(C)(C)O[C@H]2[C@H]([C@H](O)/C=C/CO)N1O</smiles>

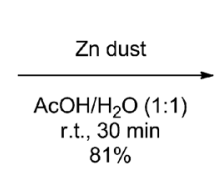<smiles>CC(C)OC[C@H]1N[C@H]([C@H](O)/C=C/CO)[C@@H]2OC(C)(C)O[C@@H]21</smiles>

Scheme 3 Synthesis of pyrrolidine intermediate 4 via Wittig olefination of 5 with stable phosphorous ylide 11.

$78 \%$ yield (Scheme 3). Up to four equivalents of DIBAL-H were necessary for the complete consumption of the starting material. THF was also examined as a possible solvent, however, this reaction was not brought to completion even with additional amount of DIBAL-H. Finally, the reductive cleavage of the $\mathrm{N}-\mathrm{O}$ bond of the hydroxylamine group in $\mathbf{1 3}$ was carried out with zinc powder in aqueous acetic acid. ${ }^{\mathbf{1 2}}$ The reaction proceeded smoothly at room temperature, affording desired pyrrolidine 4 in an excellent $81 \%$ yield already after 30 minutes.

\section{Synthesis of $(+)$-hyacinthacine $C_{3}$ and its C-5 epimer}

In order to prepare the desired pyrrolizidines, we were ready to examine the proposed iodine-mediated amino cyclisation reaction of $4 .{ }^{13}$ Its treatment with iodine in ethyl acetate in the presence of potassium carbonate at $-20^{\circ} \mathrm{C}$ afforded the 5-endotrig cyclisation products as a mixture of two diastereomers 14 and 15 in a 55 : 45 ratio (Scheme 4), as determined by ${ }^{1} \mathrm{H}$ NMR of the crude reaction mixture. To avoid problems associated with chromatographic separation of each individual isomer,

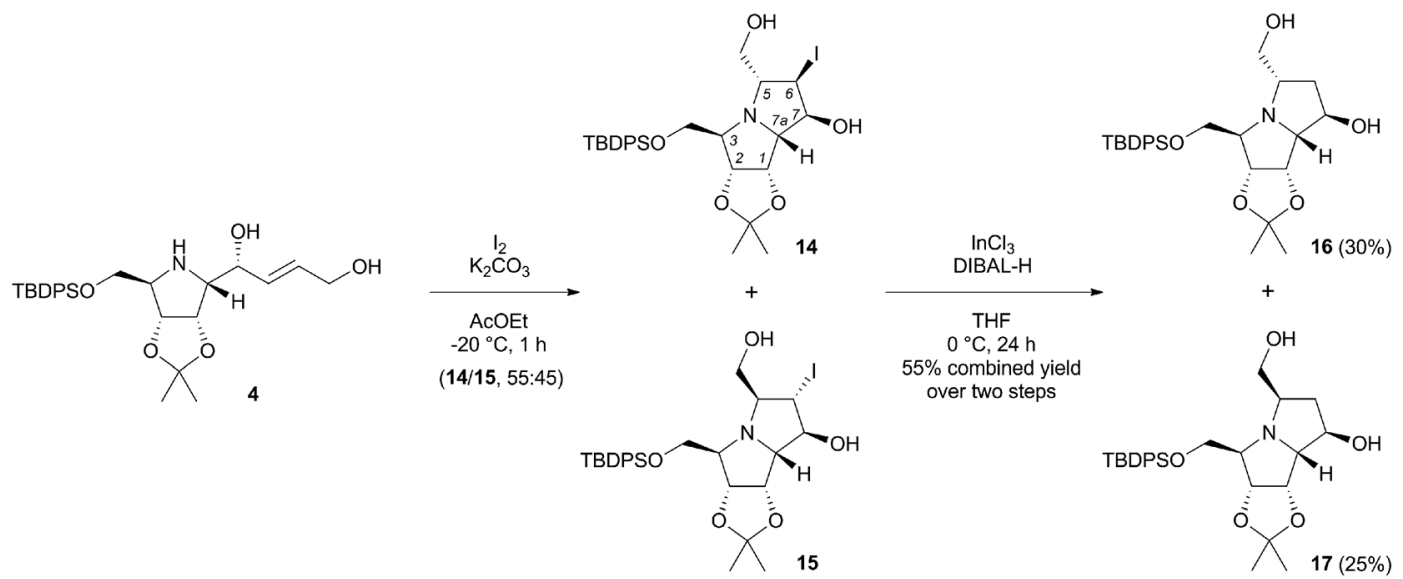

Scheme 4 Intramolecular iodoamination of pyrrolidine 4 followed by $\mathrm{InCl}_{3}$ mediated reductive dehalogenation. 
that has emerged during this process, the isomers were isolated as product mixture and used directly in the next reaction. To determine the stereochemistry of the iodo-pyrrolizidines, a sample of the mixture was subjected to repeated preparative thin-layer chromatography to obtain both isomers in pure form. Their respective structures as well as the relative configurations were determined based on ${ }^{1} \mathrm{H}$ and ${ }^{13} \mathrm{C}$ NMR spectra, including COSY, HSQC and 1D NOESY experiments (ESI $\dagger$ ). The NOE interactions between $\mathrm{H}-6$ and $\mathrm{H}-7$ protons in 14 were considerably stronger $(2.9 \%)$ compared to the same interactions in $\mathbf{1 5}$ $(0.4 \%)$. Very similar weak interactions were observed for $\mathrm{H}-5$ and H-6 protons in both diastereomers $14(0.3 \%)$ and 15 $(0.3 \%)$. This corresponded with their expected trans orientation that arises from the mechanism of the intramolecular iodoamination. For the minor 5,6-trans-6,7-trans isomer 15, several other interactions were detected, especially between $\mathrm{H}-3$ and $\mathrm{H}$ 5 protons (2.4\%), H-6 and $\mathrm{H}-7$ a protons $(1.1 \%)$ and between $\mathrm{H}-5$ and $\mathrm{H}-7$ (1.0\%). Next, the dehalogenation of pyrrolizidines 14 and $\mathbf{1 5}$ was achieved under conditions adapted from literature for related pyrrolidine derivatives, ${ }^{\mathbf{1 4}}$ where $\mathrm{InCl}_{3}$ together with a suitable hydride acts as a reducing agent. In our case, the use of $\mathrm{InCl}_{3}$ (2 equiv.) and DIBAL-H (10 equiv.) in THF at $0{ }^{\circ} \mathrm{C}$ resulted in formation of the desired C- 6 unsubstituted products 16 and 17 in 30 and 25\% yields, respectively, after two steps (Scheme 4). Strictly anhydrous conditions in an argon atmosphere were required to avoid the formation of C- 6 hydroxylated by-products. It is worth noting that the typical radical dehalogenation with $\mathrm{Bu}_{3} \mathrm{Sn}$ catalysed by AIBN failed.

Pyrrolizidines $\mathbf{1 6}$ and $\mathbf{1 7}$ were next used individually in the fluoride-mediated desilylation (Scheme 5). The reaction was carried out with CsF (5 equiv.) in $\mathrm{MeOH}$ at $50{ }^{\circ} \mathrm{C}$, and the desilylated products 18 and 19 were obtained in very good 85 and 95\% yields, respectively. The primary screening of deprotection agents has shown, that the most common reagent TBAF is not suitable for this transformation, as it contains trace amounts of $\mathrm{Bu}_{3} \mathrm{~N}$ that contaminated the final product irretrievably. ${ }^{15}$ Eventually, hydrolysis of the acetonide protecting group with acidic ion exchange resin Dowex 50WX-8 in $\mathrm{MeOH}$ was carried out. ${ }^{16}$
After washing the resin with aqueous ammonia, target (+)-hyacinthacine $\mathrm{C}_{3}(2 \mathrm{a})$ and (+)-5-epi-hyacinthacine $\mathrm{C}_{3}(2 \mathrm{~b})$ were obtained in almost quantitative 94 and 95\% isolated yields, respectively. Their structures were assigned based on ${ }^{1} \mathrm{H},{ }^{13} \mathrm{C}$ NMR, COSY and HSQC spectra, as well as extensive 1D NOESY experiments (ESI $\dagger$ ). For 2a, strong NOE interactions between $\mathrm{H}-2$ and $\mathrm{H}-1, \mathrm{H}-1$ and $\mathrm{H}-7 \mathrm{a}, \mathrm{H}-7$ and $\mathrm{H}-6 \mathrm{~b}, \mathrm{H}-6 \mathrm{a}$ and $\mathrm{H}-5$ were observed. No interaction between the $\mathrm{H}-5$ and $\mathrm{H}-3$ protons was detected, which supports its 3,5-trans configuration.

On the other hand, strong $4.2 \%$ interaction was identified between $\mathrm{H}-5$ and $\mathrm{H}-3$ in case of $\mathbf{2 b}$, thus proving the cis orientation of the two hydroxymethyl substituents. The obtained ${ }^{1} \mathrm{H}$ and ${ }^{13} \mathrm{C}$ NMR spectra were compared to the previously gathered data for synthetic (+)-hyacinthacine $\mathrm{C}_{3}$ and its C- 5 epimer by Yoda et al., 2009, ${ }^{4}$ as well as with the spectroscopic data of the natural sample (Kato et al., 2007). ${ }^{3}$ While our data were in good agreement with those described by Yoda for both of the compounds (with a little exception for the $\mathrm{H}-3, \mathrm{H}-5$ and $\mathrm{H}-7 \mathrm{a}$ protons, whose chemical shift may be affected by a different chemical environment during the process of isolating and purifying), ${ }^{17}$ they were evidently inconsistent (in particular, ${ }^{3} J_{\mathrm{H}^{-}}$ ${ }_{\mathrm{H}}$ coupling constants and ${ }^{13} \mathrm{C}$ chemical shifts) with the characteristics of the natural sample of the compound isolated and identified as (+)-hyacinthacine $\mathrm{C}_{3}$ by Kato et al. (ESI, Tables S1 and $\mathrm{S} 2 \dagger)$. To our delight, the optical rotation value for $\mathbf{2 a}$ $\left\{[\alpha]_{\mathrm{D}}^{22}=+9.3\left(c 0.3, \mathrm{H}_{2} \mathrm{O}\right)\right\}$ closely resembled the value of the optical rotation for the (+)-hyacinthacine $\mathrm{C}_{3}\left\{[\alpha]_{\mathrm{D}}^{22}=+8.8(c 0.3\right.$, $\left.\mathrm{H}_{2} \mathrm{O}\right)$, previously prepared by Yoda et al. ${ }^{4}$ Similarly, the value of

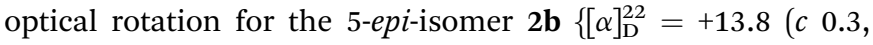
$\left.\left.\mathrm{H}_{2} \mathrm{O}\right)\right\}$ was in agreement with the published data for $(+)-5$-epihyacinthacine $\mathrm{C}_{3}(+)$-hyacinthacine $\mathrm{C}_{3}\left\{[\alpha]_{\mathrm{D}}^{22}=+14.8\right.$ (c 0.3 , $\left.\left.\mathrm{H}_{2} \mathrm{O}\right)\right\}$. The above-mentioned evidence supports the argument, that the original structure proposed for $(+)$-hyacinthacine $\mathrm{C} 3$, isolated from natural source, is incorrect.

\section{Evaluation of antiproliferative effect on human cancer cells}

Previously published experimental data showed significant inhibitory effect of hyacinthacines towards many types of
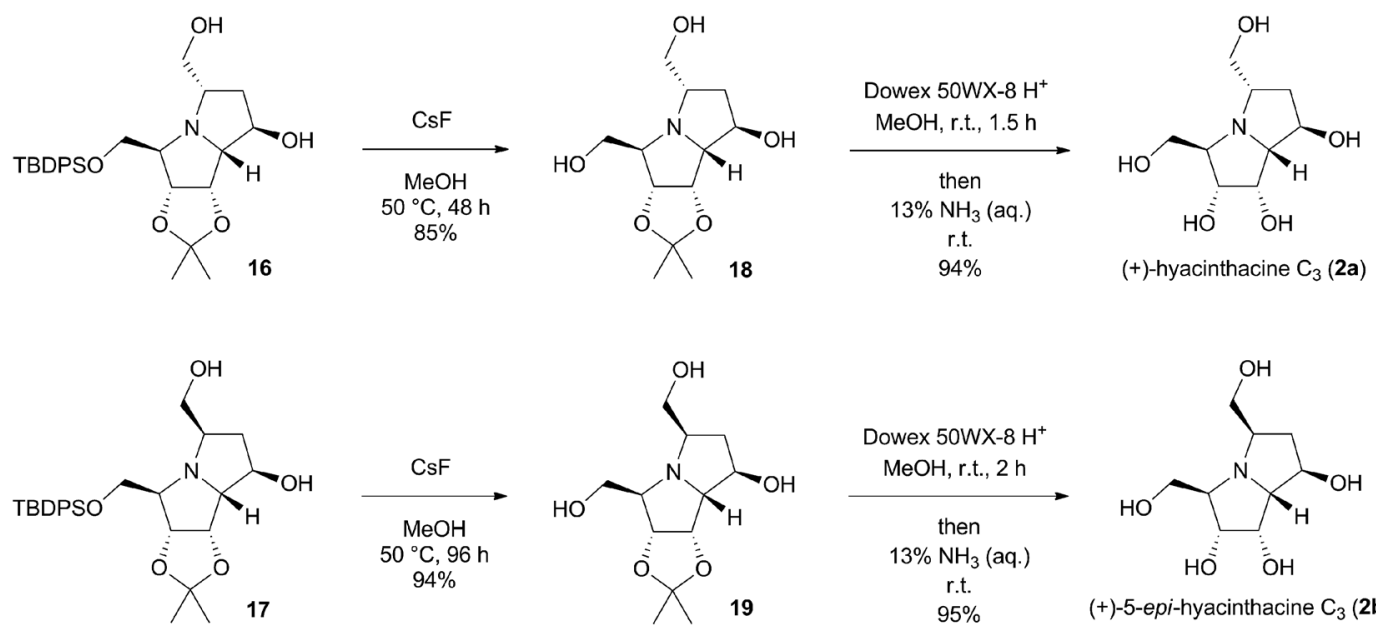

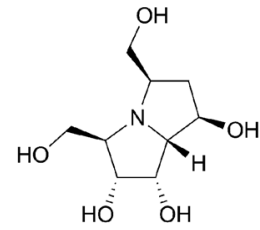

(+)-5-epi-hyacinthacine $\mathrm{C}_{3}(\mathbf{2 b})$

Scheme 5 Synthesis of (+)-hyacinthacine $C_{3}(2 a)$ and (+)-5-epi-hyacinthacine $C_{3}(2 b)$. 
glycosidases. ${ }^{5 \boldsymbol{b}}$ Since glycosidase inhibitors were established as possible treatments for tumor metastasis, ${ }^{5 \boldsymbol{b}}$ the prepared synthetic hyacinthacine C3 (2a) and its C-5 epimer 2b were evaluated for its potential antiproliferative effect. The effect was examined on three different cancer cell lines U87-MG, HepG2 and JEG-3 as well as immortalized proximal tubular cells HK2. $\mathrm{IC}_{50}$ values of all tested compounds exceeded maximal value of the tested concentration range 1-1000 $\mu \mathrm{M}$ (ESI, Table S3†). We did not confirm any significant antiproliferative activity in the tested concentrations. The finding may suggest that the proved antiglycosidase potency of the tested hyacithacines is not so strong to be manifested in very vital cancer cells. Moreover, their low antiproliferative activity may be associated with the high level of hydrophility of the polyhydroxylated pyrrolizidines. It is known that derivatization of similar hydroxylated pyrrolidines with lipophilic groups enhances their ability to penetrate cell membranes, and thus increase their efficiency in human tumor cell inhibition. ${ }^{\mathbf{1 8}}$ The lack of a lipophilic unit in the structure of the reviewed compounds may explain the obtained limited results. This fact implies that synthetized substances are not suitable for development of potential cytostatics. Due to antiglycosidase activity, hyacinthacines may exert a potency against viral infection and various lysosomal storage disorders. ${ }^{5 b}$ Therefore, the found low cytotoxicity can be a positive impulse for considerations of further studies on utilization of these potential effects.

\section{Conclusions}

In summary, we have designed a new synthetic pathway towards structurally interesting polyhydroxylated pyrrolizidine alkaloids bearing two hydroxymethyl substituents at C-3 and C-5 and a hydroxy substituent at C-7 position. (+)-Hyacinthacine $\mathrm{C}_{3}$ and $(+)-5$-epi-hyacinthacine $\mathrm{C}_{3}$ were prepared from cyclic $\mathrm{L}$-mannose derived nitrone, which underwent a highly stereoselective 1,3dipolar cycloaddition, building up majority of the desired stereocenters. The following key steps included Wittig olefination that provided a necessary alkene basis for iodocyclisation, that afforded two pyrrolizidine isomers, that were eventually transformed into the desired compounds. $(+)$-Hyacinthacine $\mathrm{C}_{3}$ and $(+)-5$-epi-hyacinthacine $\mathrm{C}_{3}$ were prepared in 13 steps starting from the sugar derived nitrone in $6 \%$ and $5 \%$ yield, respectively. This total synthesis supports previously synthetically acquired data for these compounds, while disproving the structural proposal for the naturally occurring sample. Although the hyacinthacine C-type alkaloids exhibit inherent glycosidase inhibitory activities, synthetic hyacinthacine $\mathrm{C}_{3}$ and its C-5 epimer showed no antiproliferative activity against selected human cancer cell lines in vitro. On the other hand, the insignificant cytotoxicity forms a good base for employment of other biological effects of the tested compounds.

\section{Experimental section}

\section{General methods}

Melting points were measured with a Melting Point B-540 apparatus (Büchi). Flash column chromatography (FCC) was carried out with a Büchi system (Pump Manager C-615 and Fraction Collector C-660) using Normasil 60 silica gel (0.040$0.063 \mathrm{~mm}$; VWR). Thin Layer Chromatography (TLC) analysis was carried out using TLC silica gel $60 F_{254}$ (aluminium sheets, Merck), and plates were visualized with UV light or by treatment with permanganate solution followed by heating. Optical rotations were measured with a JASCO P-2000 digital polarimeter with a Na-D lamp (10 cm cell length). Concentrations $(c)$ are given in gram per $100 \mathrm{~mL}$. Infrared (IR) spectra were recorded as neat samples with a Nicolet 5700 FTIR spectrometer with an ATR Smart Orbit Diamond adapter (Thermo Electron Corporation). NMR spectra were recorded with a Varian INOVA-300 spectrometer $\left({ }^{1} \mathrm{H}, 299.95 \mathrm{MHz}\right.$, and $\left.{ }^{13} \mathrm{C}, 75.42 \mathrm{MHz}\right)$ and a Varian VNMRS-600 instrument $\left({ }^{1} \mathrm{H}, 599.75 \mathrm{MHz}\right.$, and ${ }^{13} \mathrm{C}, 150.81$ $\mathrm{MHz}$ ) in $\mathrm{CDCl}_{3}$ (using tetramethylsilane as the internal standard), in $\mathrm{CD}_{3} \mathrm{OD}$ (residual $\left[\mathrm{D}_{3}\right]$ methanol, $\delta_{\mathrm{H}}=3.31,4.87 \mathrm{ppm}$, $\delta_{\mathrm{C}}=49.00 \mathrm{ppm}$ ), and in $\mathrm{D}_{2} \mathrm{O}$ (using TSP- $d_{4}$ as the internal standard, $\left.\delta_{\mathrm{H}, \mathrm{C}}=0.00 \mathrm{ppm}\right)$. Data are presented as follows: chemical shift, multiplicity, coupling constants and integration. ${ }^{1} \mathrm{H}$ and ${ }^{13} \mathrm{C}$ signals were assigned by $2 \mathrm{D}$ experiments (COSY and HSQC). HRMS analysis was carried out with an Orbitrap Velos Pro spectrometer (Thermo Fisher Scientific). Dichloromethane was distilled in the presence of calcium hydride. Tetrahydrofuran was distilled in the presence of sodium. Anhydrous ethyl acetate (Sigma-Aldrich), N,N-dimethylformamide (Acros Organics) and acetic acid (Acros Organics) were used as received. Simple distillation was used to purify other solvents prior to use if not stated otherwise. Phosphorus ylide 11 was commercially available. The pyrrolizidine ring protons in compounds 14-19 have been designated as follows: $\mathrm{H}-1, \mathrm{H}-2, \mathrm{H}-$ 3 , H-5, H-6, H-7, and $\mathrm{H}-7 \mathrm{a}$, regardless of their naming.

$(2 R, 3 S, 3 \mathrm{a} S, 4 S, 5 R, 6 R)-6$-[(R)-1,2-Dihydroxyethyl]-4,5-isopropylidenedioxyhexahydropyrrolo[1,2-b]isoxazol-2,3-diyl carbonate (8). Isoxazolidine exo-syn-6 (2.83 g, $8.24 \mathrm{mmol}, 1$ equiv.) was dissolved in ethanol $(165 \mathrm{~mL})$ and $p-\mathrm{TSA} \cdot \mathrm{H}_{2} \mathrm{O}$ (470 $\mathrm{mg}, 2.47 \mathrm{mmol}, 0.3$ equiv.) was added. The reaction mixture was stirred at $60{ }^{\circ} \mathrm{C}$ for $6 \mathrm{~h}$. After TLC (EtOAc) showed complete disappearance of the starting material, the solvent was removed under reduced pressure. The residue was purified by FCC (hexanes/EtOAc $1: 9)$ to give diol 8 (2.27 g, $7.49 \mathrm{mmol}$, $91 \%)$ as a white solid.

$R_{\mathrm{f}}=0.26$ (EtOAc), $\mathrm{mp}=153-155^{\circ} \mathrm{C},[\alpha]_{\mathrm{D}}^{25}=+139.9(c 1.02$, MeOH). IR (ATR) $\nu_{\text {max }}: 3477 ; 2937 ; 1789 ; 1377 ; 1190 ; 1043 ; 982$; $864 ; 770 ; 722 ; 516 \mathrm{~cm}^{-1} .{ }^{1} \mathrm{H}$ NMR (600 MHz, CD $\left.3 \mathrm{OD}\right) \delta(\mathrm{ppm})$ 1.29 (s, $3 \mathrm{H}, \mathrm{CH}_{3}$ ), $1.40\left(\mathrm{~s}, 3 \mathrm{H}, \mathrm{CH}_{3}\right), 3.56$ (dd, $J=6.2,11.0 \mathrm{~Hz}$, $\left.1 \mathrm{H}, \mathrm{H}-2^{\prime}{ }_{\mathrm{a}}\right), 3.69\left(\mathrm{dd}, J=6.3,11.0 \mathrm{~Hz}, 1 \mathrm{H}, \mathrm{H}-2^{\prime}{ }_{\mathrm{b}}\right), 3.77(\mathrm{td}, J=3.0$, $6.2 \mathrm{~Hz}, 1 \mathrm{H}, \mathrm{H}-1^{\prime}$ ), 3.99 (d, $\left.J=2.9 \mathrm{~Hz}, 1 \mathrm{H}, \mathrm{H}-6\right), 4.05$ (d, $J=5.3 \mathrm{~Hz}$, $1 \mathrm{H}, \mathrm{H}-3 \mathrm{a}$ ), 4.89 (pseudo t, $J=5.6,6.0 \mathrm{~Hz}, 1 \mathrm{H}, \mathrm{H}-4$ ), 4.98 (d, $J=$ $6.3 \mathrm{~Hz}, 1 \mathrm{H}, \mathrm{H}-5), 5.67$ (d, $J=5.2 \mathrm{~Hz}, 1 \mathrm{H}, \mathrm{H}-3), 6.13$ (d, $J=5.2 \mathrm{~Hz}$, $1 \mathrm{H}, \mathrm{H}-2) .{ }^{13} \mathrm{C}$ NMR (150 MHz, $\left.\mathrm{CD}_{3} \mathrm{OD}\right) \delta(\mathrm{ppm}) 23.9\left(\mathrm{CH}_{3}\right), 26.5$ $\left(\mathrm{CH}_{3}\right), 64.5\left(\mathrm{C}-5^{\prime}\right), 73.4\left(\mathrm{C}-4^{\prime}\right), 74.1$ (C-6), 75.8 (C-3a), 83.2 (C-4), 87.0 (C-3), 88.6 (C-5), 103.0 (C-2), $114.0\left[\mathrm{C}\left(\mathrm{CH}_{3}\right)_{2}\right], 155.6(\mathrm{C}=$ O). HRMS (ESI) $m / z$ : for $\mathrm{C}_{12} \mathrm{H}_{17} \mathrm{NNaO}_{8}[\mathrm{M}+\mathrm{Na}]^{+}$, calcd: 326.0847; found: 326.0848 .

$(2 R, 3 S, 3 \mathrm{a} S, 4 S, 5 R, 6 R)-6$-(Hydroxymethyl)-4,5-isopropylidenedioxyhexahydropyrrolo[1,2-b]isoxazol-2,3-diyl carbonate (9). Diol 8 (2.20 g, $7.25 \mathrm{mmol}, 1$ equiv.) was dissolved 
in aqueous $\mathrm{MeOH}\left(\mathrm{MeOH} / \mathrm{H}_{2} \mathrm{O} 9: 1,145 \mathrm{~mL}\right)$ and the mixture was cooled down to $0{ }^{\circ} \mathrm{C}$ in an ice/water bath. Afterwards, $\mathrm{NaIO}_{4}$ powder (2.33 g, $10.88 \mathrm{mmol}, 1.5$ equiv.) was slowly added and the reaction mixture was gradually warmed up to room temperature and stirred for $12 \mathrm{~h}$. When TLC $\left(\mathrm{CH}_{2} \mathrm{Cl}_{2} / \mathrm{MeOH}\right.$ $9: 1)$ showed that the reaction was complete, the mixture was cooled down to $0{ }^{\circ} \mathrm{C}$ again and solid $\mathrm{NaBH}_{4}(550 \mathrm{mg}, 14.5 \mathrm{mmol}$, 2 equiv.) was added. The reaction was stirred at room temperature for $2 \mathrm{~h}$, until TLC $\left(\mathrm{CH}_{2} \mathrm{Cl}_{2} / \mathrm{MeOH} 9: 1\right)$ showed complete disappearance of the aldehyde. After this time, the suspension was diluted with saturated aqueous solution of $\mathrm{NH}_{4} \mathrm{Cl}(20 \mathrm{~mL})$, and methanol was partially removed under reduced pressure. The residue was diluted saturated aqueous solution of $\mathrm{NaCl}$ $(100 \mathrm{~mL})$ and extracted with EtOAc $(4 \times 60 \mathrm{~mL})$. The combined organic layers were dried over $\mathrm{MgSO}_{4}$, filtered, and concentrated under reduced pressure. The residue was purified by FCC $\left(\mathrm{CH}_{2} \mathrm{Cl}_{2} / \mathrm{MeOH} 85: 15\right)$ to give alcohol 9 (1.58 g, $5.78 \mathrm{mmol}$, $80 \%$ over two steps) as a white solid.

$R_{\mathrm{f}}=0.46$ (EtOAc), $\mathrm{mp}=209-211^{\circ} \mathrm{C},[\alpha]_{\mathrm{D}}^{25}=-79.6(c 0.97$, MeOH). IR (ATR) $\nu_{\text {max }}: 3272 ; 3002 ; 2928 ; 1823 ; 1383 ; 1208 ; 1157$; 1063; 995; 850; 768; $519 \mathrm{~cm}^{-1} .{ }^{1} \mathrm{H}$ NMR (600 MHz, $\left.\mathrm{CD}_{3} \mathrm{OD}\right)$ $\delta(\mathrm{ppm}) 1.29\left(\mathrm{~s}, 3 \mathrm{H}, \mathrm{CH}_{3}\right), 1.40\left(\mathrm{~s}, 3 \mathrm{H}, \mathrm{CH}_{3}\right), 3.62(\mathrm{dd}, J=4.2$, $11.3 \mathrm{~Hz}, 1 \mathrm{H}, \mathrm{CH}_{2} \mathrm{OH}$ ), 3.67 (dd, $J=4.5,11.3 \mathrm{~Hz}, 1 \mathrm{H}, \mathrm{CH}_{2} \mathrm{OH}$ ), $3.86(\mathrm{t}, J=4.3 \mathrm{~Hz}, 1 \mathrm{H}, \mathrm{H}-6), 4.05$ (d, $J=5.2 \mathrm{~Hz}, 1 \mathrm{H}, \mathrm{H}-3 \mathrm{a}), 4.89$ (pseudo t, $J=5.5,6.0 \mathrm{~Hz}, 1 \mathrm{H}, \mathrm{H}-4), 4,94(\mathrm{~d}, J=6.3 \mathrm{~Hz}, 1 \mathrm{H}, \mathrm{H}-5$ ), 5.68 (d, $J=5.2 \mathrm{~Hz}, 1 \mathrm{H}, \mathrm{H}-3), 6.15$ (d, $J=5.2 \mathrm{~Hz}, 1 \mathrm{H}, \mathrm{H}-2) .{ }^{13} \mathrm{C}$ NMR (150 MHz, CD $3 \mathrm{OD}) \delta(\mathrm{ppm}) 23.9\left(\mathrm{CH}_{3}\right), 26.4\left(\mathrm{CH}_{3}\right), 62.5(\mathrm{C}-$ $4^{\prime}$ ), 74.5 (C-6), 75.2 (C-3a), 83.3 (C-4), 86.8 (C-3), 87.1 (C-5), 103.1 (C-2), $114.1\left[\underline{\mathrm{C}}\left(\mathrm{CH}_{3}\right)_{2}\right], 155.5(\mathrm{C}=\mathrm{O})$. HRMS (ESI) $\mathrm{m} / \mathrm{z}$ : for $\mathrm{C}_{11} \mathrm{H}_{15} \mathrm{NNaO}_{7}[\mathrm{M}+\mathrm{Na}]^{+}$, calcd: 296.0741; found: 296.0740.

$(2 R, 3 S, 3 a S, 4 S, 5 R, 6 R)-6$-[(terc-Butyldiphenylsilyl)oxymethyl]4,5-isopropylidenedioxyhexahydropyrrolo[1,2-b]isoxazol-2,3-

diyl carbonate (10). To a stirred solution of isoxazolidine 9 (1.52 g, $5.56 \mathrm{mmol}, 1$ equiv.) in DMF $(55 \mathrm{~mL})$ was at $0{ }^{\circ} \mathrm{C}$ added imidazole (1.29 g, $18.95 \mathrm{mmol}, 3.4$ equiv.) and tert-butyldiphenylsilyl chloride (2.42 mL, $9.44 \mathrm{mmol}, 1.7$ equiv.). The resulting mixture was stirred at room temperature for $18 \mathrm{~h}$. After TLC (hexanes/EtOAc $2: 3$ ) showed complete disappearance of the starting material, water $(50 \mathrm{~mL})$ was added, and the mixture was extracted with $\mathrm{CH}_{2} \mathrm{Cl}_{2}(3 \times 50 \mathrm{~mL})$. The combined organic layers were dried over $\mathrm{MgSO}_{4}$, filtered, and concentrated under reduced pressure. The residue was purified by FCC (hexanes/ EtOAc $80: 20)$ to give isoxazolidine 10 (2.63 g, $5.14 \mathrm{mmol}$, $92 \%)$ as a white solid.

$R_{\mathrm{f}}=0.25$ ( $n$-hexane/EtOAc $\left.3: 1\right), \mathrm{mp}=145-148^{\circ} \mathrm{C},[\alpha]_{\mathrm{D}}^{25}=$ -44.2 (c 1.035, $\mathrm{CHCl}_{3}$ ). IR (ATR) $\nu_{\max }: 2931 ; 2860 ; 1812 ; 1373$; 1107; 1062; 990; 742; 701; 615; $503 \mathrm{~cm}^{-1} .{ }^{1} \mathrm{H}$ NMR $(600 \mathrm{MHz}$, $\left.\mathrm{CDCl}_{3}\right) \delta(\mathrm{ppm}) 1.04(\mathrm{~s}, 9 \mathrm{H}, \mathrm{Sit}-\mathrm{Bu}), 1.29\left(\mathrm{~s}, 3 \mathrm{H}, \mathrm{CH}_{3}\right), 1.42(\mathrm{~s}, 3 \mathrm{H}$, $\mathrm{CH}_{3}$ ), 3.77 (dd, $J=3.4,10.7 \mathrm{~Hz}, 1 \mathrm{H}, \mathrm{CH}_{2} \mathrm{OSi}$ ), 3.90 (dd, $J=2.5$, $10.7 \mathrm{~Hz}, 1 \mathrm{H}, \mathrm{CH}_{2} \mathrm{OSi}$ ), 3.94 (t, $\left.J=2.8 \mathrm{~Hz}, 1 \mathrm{H}, \mathrm{H}-6\right), 4.15$ (d, $J=$ $5.3 \mathrm{~Hz}, 1 \mathrm{H}, \mathrm{H}-3 \mathrm{a}$ ), 4.88 (pseudo t, $J=5.6,5.9 \mathrm{~Hz}, 1 \mathrm{H}, \mathrm{H}-4$ ), 4.98 $(\mathrm{d}, J=6.2 \mathrm{~Hz}, 1 \mathrm{H}, \mathrm{H}-5), 5.60(\mathrm{~d}, J=5.2 \mathrm{~Hz}, 1 \mathrm{H}, \mathrm{H}-3), 6.02(\mathrm{~d}, J=$ $5.2 \mathrm{~Hz}, 1 \mathrm{H}, \mathrm{H}-2)$, 7.39-7.47 (m, 6H, H-Ph), 7.59-7.63 (m, 4H, H$\mathrm{Ph}) .{ }^{13} \mathrm{C} \mathrm{NMR}\left(150 \mathrm{MHz}, \mathrm{CDCl}_{3}\right) \delta(\mathrm{ppm}) 19.2\left[\mathrm{SiC}\left(\mathrm{CH}_{3}\right)_{3}\right], 23.8$ $\left(\mathrm{CH}_{3}\right), 26.3\left(\mathrm{CH}_{3}\right), 27.1\left[\mathrm{SiC}\left(\underline{\mathrm{CH}}_{3}\right)_{3}\right], 64.5\left(\mathrm{C}-4^{\prime}\right), 73.0(\mathrm{C}-6), 74.5$ (C-3a), 82.3 (C-4). 85.2 (C-3), 86.2 (C-5), 101.1 (C-2), 113.3 $\left[\underline{\mathrm{C}}\left(\mathrm{CH}_{3}\right)_{2}\right], 128.1(\mathrm{CH}, \mathrm{Ph}), 128.2(\mathrm{CH}, \mathrm{Ph}), 130.2(\mathrm{CH}, \mathrm{Ph}), 130.3$
(CH, Ph), 132.1 (C, Ph), 132.3 (C, Ph), 135.5 (CH, Ph), 135.7 (CH, $\mathrm{Ph}), 153.3(\mathrm{C}=\mathrm{O})$. HRMS (ESI) $m / z$ : for $\mathrm{C}_{27} \mathrm{H}_{33} \mathrm{NNaO}_{7} \mathrm{Si}[\mathrm{M}+\mathrm{H}]^{+}$, calcd: 534.1919; found: 534.1919).

$(3 S, 3 a R, 4 S, 5 R, 6 R)-6-[($ terc-Butyldiphenylsilyl)oxymethyl]-4,5isopropylidenedioxyhexahydropyrrolo[1,2-b]isoxazol-2,3-diol

(5). Isoxazolidine 10 (2.53 g, $4.94 \mathrm{mmol}, 1$ equiv.) was dissolved in aqueous methanol $\left(\mathrm{MeOH} / \mathrm{H}_{2} \mathrm{O} 2: 1,50 \mathrm{~mL}\right), \mathrm{Et}_{3} \mathrm{~N}(6.9 \mathrm{~mL}$, $49.5 \mathrm{mmol}, 10$ equiv.) was added at room temperature and the mixture was stirred for $24 \mathrm{~h}$ at $50{ }^{\circ} \mathrm{C}$. The progress of the reaction was monitored by TLC (EtOAc). After the starting material was not detected in the reaction mixture anymore, $\mathrm{MeOH}$ was partially evaporated under reduced pressure. The residue was combined with saturated aqueous solution of $\mathrm{NaCl}(100 \mathrm{~mL})$, and the mixture was extracted with $\mathrm{CH}_{2} \mathrm{Cl}_{2}(3 \times 100 \mathrm{~mL})$. The combined organic layers were dried over $\mathrm{MgSO}_{4}$, filtered, and concentrated under reduced pressure. The residue was purified by FCC (hexanes/EtOAc $2: 3$ ) to give an anomeric mixture of isoxazolidine diol $5(2.23 \mathrm{~g}, 4.59 \mathrm{mmol}, 93 \%$, anomeric ratio = $90: 10)$ as a white solid foam.

$R_{\mathrm{f}}=0.50$ ( $n$-hexane/EtOAc $\left.1: 4\right)$. IR (ATR) $\nu_{\max }: 3406 ; 2931$; $2856 ; 1427 ; 1372 ; 1104 ; 9933 ; 822 ; 740 ; 700 ; 501 \mathrm{~cm}^{-1}$. NMR data selected from the anomeric mixture after purification: ${ }^{1} \mathrm{H}$ NMR (600 MHz, $\mathrm{CDCl}_{3}$, major anomer) $\delta$ (ppm) 1.05 (s, 9H, Sit-Bu), $1.28\left(\mathrm{~s}, 3 \mathrm{H}, \mathrm{CH}_{3}\right), 1.42\left(\mathrm{~s}, 3 \mathrm{H}, \mathrm{CH}_{3}\right), 3.41$ (bs, $\left.1 \mathrm{H}, \mathrm{C} 3-\mathrm{OH}\right), 3.74-$ 3.77 (m, 2H, $\mathrm{CH}_{2} \mathrm{OSi}, \mathrm{H}-6$ ), 3.80-3.83 (m, 2H, $\mathrm{CH}_{2} \mathrm{OSi}, \mathrm{H}-3 \mathrm{a}$ ), 4.55 (bs, 1H, C2- $\underline{\mathrm{OH}}$ ), 4.82 (pseudo t, $J=5.7,6.2 \mathrm{~Hz}, 1 \mathrm{H}, \mathrm{H}-4$ ), $4.86(\mathrm{~d}, J=6.4 \mathrm{~Hz}, 1 \mathrm{H}, \mathrm{H}-5), 4.88$ (d, $J=5.3 \mathrm{~Hz}, 1 \mathrm{H}, \mathrm{H}-3)$, 5.36 (d, $J=5.3 \mathrm{~Hz}, 1 \mathrm{H}, \mathrm{H}-2)$, 7.37-7.45 (m, 6H, H-Ph), 7.617.64 (m, 4H, H-Ph). ${ }^{13} \mathrm{C}$ NMR (150 MHz, $\mathrm{CDCl}_{3}$, major anomer) $\delta(\mathrm{ppm}) \quad 19.3\left[\mathrm{Si} \underline{(}\left(\mathrm{CH}_{3}\right)_{3}\right], \quad 24.1 \quad\left(\mathrm{CH}_{3}\right), 26.4\left(\mathrm{CH}_{3}\right), 27.1$ $\left[\mathrm{SiC}\left(\mathrm{CH}_{3}\right)_{3}\right], 64.6\left(\mathrm{C}-4^{\prime}\right), 72.4(\mathrm{C}-6), 76.6(\mathrm{C}-3), 77.4(\mathrm{C}-3 \mathrm{a}), 82.4(\mathrm{C}-$ 5), 85.5 (C-4), 95.6 (C-2), $112.8\left[\mathrm{C}\left(\mathrm{CH}_{3}\right)_{2}\right], 127.9$ (CH, Ph), 128.0 (CH, Ph), 130.1 (CH, Ph), 130.2 (CH, Ph), 132.6 (C, Ph), 132.8 (C, $\mathrm{Ph}), 135.8(2 \times \mathrm{CH}, \mathrm{Ph})$. HRMS (ESI + APCI) $m / z$ : for $\mathrm{C}_{26} \mathrm{H}_{36} \mathrm{NO}_{6} \mathrm{Si}$ $[\mathrm{M}+\mathrm{H}]^{+}$, calcd: 486.2307 ; found: 486.2.

$(R, E)$-Ethyl $\quad 4-\{(2 R, 3 S, 4 R, 5 R)-5-[($ tert-butyldiphenylsilyl $)$ oxymethyl]-1-hydroxy-3,4-isopropylidenedioxypyrrolidin-2-yl\}-4hydroxybut-2-enoate (12). Isoxazolidine 5 (1.46 g, $3.0 \mathrm{mmol}, 1$ equiv.) were dissolved in dichloromethane $(30 \mathrm{~mL})$, phosphorus ylide 11 was added ( $2.09 \mathrm{~g}, 6.0 \mathrm{mmol} ; 2$ equiv.) and the solution was stirred at room temperature for $48 \mathrm{~h}$. After TLC showed complete disappearance of the starting material (hexanes/ EtOAc $1: 1)$ the solvent was removed under reduced pressure. The residue was purified by FCC (hexanes/EtOAc $3: 1$ ) to give ester $12(1.48 \mathrm{~g}, 2.66 \mathrm{mmol}, 89 \%)$ as a white solid foam.

$R_{\mathrm{f}}=0.25$ (n-hexane/EtOAc $\left.3: 2\right), \mathrm{mp}=51-54{ }^{\circ} \mathrm{C},[\alpha]_{\mathrm{D}}^{25}=$ -20.4 (c 1.01, $\mathrm{CHCl}_{3}$ ). IR (ATR) $\nu_{\text {max }}: 3408 ; 2933 ; 1819 ; 1716$; $1372 ; 1160 ; 1055 ; 973 ; 822 ; 701 ; 613 ; 503 \mathrm{~cm}^{-1} .{ }^{1} \mathrm{H}$ NMR $(600$ $\left.\mathrm{MHz}, \mathrm{CDCl}_{3}\right) \delta(\mathrm{ppm}){ }^{1} \mathrm{H} \mathrm{NMR}\left(600 \mathrm{MHz}, \mathrm{CDCl}_{3}\right): 1.04$ (s, 9H, Sit$\mathrm{Bu}), 1.25\left(\mathrm{~s}, 3 \mathrm{H}, \mathrm{CH}_{3}\right), 1.30\left(\mathrm{t}, J=7.2 \mathrm{~Hz}, 1 \mathrm{H}, \mathrm{CH}_{2} \mathrm{CH}_{3}\right), 1.41(\mathrm{~s}$, $\left.3 \mathrm{H}, \mathrm{CH}_{3}\right), 3.48-3.51$ (m, $\left.1 \mathrm{H}, \mathrm{H}-5^{\prime}\right), 3.60-3.64\left(\mathrm{~m}, 1 \mathrm{H}, \mathrm{H}-2^{\prime}\right), 3.68$ (dd, $J=3.0,11.0 \mathrm{~Hz}, 1 \mathrm{H}, \mathrm{CH}_{2} \mathrm{OSi}$ ), 3.84-3.97 (m, 1H, C4-OH ), 4.17-4.25 (m, 2H, $\left.\mathrm{CH}_{2} \mathrm{CH}_{3}\right), 4.32(\mathrm{dd}, J=3.0,11.0 \mathrm{~Hz}, 1 \mathrm{H}$, $\left.\mathrm{CH}_{2} \mathrm{OSi}\right), 4.67-4.70$ (m, 2H, H-3', H-4'), 4.79 (bs, $\left.1 \mathrm{H}, \mathrm{H}-4\right), 6.20$ (dd, $J=2.0,15.5 \mathrm{~Hz}, 1 \mathrm{H}, \mathrm{H}-3$ ), 7.10 (dd, $J=4.4,15.5 \mathrm{~Hz}, 1 \mathrm{H}, \mathrm{H}-$ 2), 7.37-7.45 (m, 6H, H-Ph), $7.62-7.69$ (m, 4H, H-Ph). ${ }^{13} \mathrm{C}$ NMR 
$\left(150 \mathrm{MHz}, \mathrm{CDCl}_{3}\right) \delta(\mathrm{ppm}) 14.4\left(\underline{\mathrm{CH}_{3}} \mathrm{CH}_{2}\right), 19.2\left[\mathrm{SiC}\left(\mathrm{CH}_{3}\right)_{3}\right]$, $23.9\left(\mathrm{CH}_{3}\right), 25.8\left(\mathrm{CH}_{3}\right), 27.0\left[\mathrm{SiC}\left(\mathrm{CH}_{3}\right)_{3}\right], 60.2$ (C-6), 60.5 $\left(\mathrm{CH}_{3} \underline{\mathrm{CH}_{2}}\right), 69.0(\mathrm{C}-5), 69.8(\mathrm{C}-2), 70.1\left(\mathrm{C}-4^{\prime}\right), 78.4(\mathrm{C}-3), 79.4(\mathrm{C}-$ 4), $111.3\left[\mathrm{C}\left(\mathrm{CH}_{3}\right)_{2}\right], 121.7\left(\mathrm{C}-3^{\prime}\right), 127.9(\mathrm{CH}, \mathrm{Ph}), 128.0(\mathrm{CH}, \mathrm{Ph})$, 130.0 ( $2 \times \mathrm{CH}, \mathrm{Ph}), 132.8$ (C, Ph), 133.0 (C, Ph), 135.7 (CH, Ph), $135.8(\mathrm{CH}, \mathrm{Ph}), 148.3\left(\mathrm{C}-2^{\prime}\right), 166.6(\mathrm{C}=\mathrm{O})$. HRMS (ESI) $\mathrm{m} / \mathrm{z}$ : for $\mathrm{C}_{30} \mathrm{H}_{42} \mathrm{NO}_{7} \mathrm{Si}[\mathrm{M}+\mathrm{H}]^{+}$, calcd: 556.2726 ; found: 556.2728 .

$(R, E)-1-\{(2 R, 3 S, 4 R, 5 R)-5-[($ tert-Butyldiphenylsilyl)oxymethyl]1-hydroxy-3,4-isopropylidenedioxypyrrolidin-2-yl $\}$ but-2-ene-1,4diol (13). To a stirred solution of isoxazolidine 12 (1.4 g, $2.52 \mathrm{mmol}, 1$ equiv.) in anhydrous dichloromethane $(25 \mathrm{~mL})$ was slowly added a solution of DIBAL-H (1 M in hexane, 10.1 $\mathrm{mL}, 10.1 \mathrm{mmol}, 4$ equiv.) under Ar atmosphere and the reaction mixture was stirred at $-20{ }^{\circ} \mathrm{C}$ for 2 hours. The progress of the reaction was monitored by TLC (EtOAc). After this time, EtOAc $(60 \mathrm{~mL})$ and saturated aqueous solution of potassium sodium tartrate tetrahydrate $(60 \mathrm{~mL})$ were added, and the resulting slurry was vigorously stirred for $2 \mathrm{~h}$ at room temperature until two clear phases appeared. Afterwards, the organic layer was separated, and the aqueous layer was extracted with EtOAc $(3 \times$ $60 \mathrm{~mL}$ ). The organic layers were dried over $\mathrm{MgSO}_{4}$, filtered, and concentrated under reduced pressure. The residue was purified by FCC (EtOAc) to give alcohol $13(1.01 \mathrm{~g}, 1.97 \mathrm{mmol}, 78 \%)$ as a white solid foam.

$R_{\mathrm{f}}=0.27$ (EtOAc), $\mathrm{mp}=53-56{ }^{\circ} \mathrm{C},[\alpha]_{\mathrm{D}}^{25}=-45.4(c 1.02$, $\mathrm{CHCl}_{3}$ ). IR (ATR) $\nu_{\text {max }}: 3353 ; 2932 ; 2857 ; 1427 ; 1209 ; 1088 ; 972$; $822 ; 740 ; 700 ; 613 ; 502 \mathrm{~cm}^{-1} .{ }^{1} \mathrm{H}$ NMR $\left(600 \mathrm{MHz}, \mathrm{CDCl}_{3}\right) \delta(\mathrm{ppm})$ $1.03(\mathrm{~s}, 9 \mathrm{H}, \mathrm{Sit}-\mathrm{Bu}), 1.27$ (s, 3H, $\left.\mathrm{CH}_{3}\right), 1.41\left(\mathrm{~s}, 3 \mathrm{H}, \mathrm{CH}_{3}\right), 1.93$ (bs, $1 \mathrm{H}, \mathrm{C} 4-\mathrm{OH}), 3.48\left(\mathrm{t}, J=3.1 \mathrm{~Hz}, 1 \mathrm{H}, \mathrm{H}-5^{\prime}\right), 3.54(\mathrm{t}, J=4.9 \mathrm{~Hz}, 1 \mathrm{H}$, $\left.\mathrm{H}-2^{\prime}\right), 3.58(\mathrm{~d}, J=8.1 \mathrm{~Hz}, 1 \mathrm{H}, \mathrm{C} 1-\mathrm{OH}), 3.68(\mathrm{dd}, J=3.2,11.0 \mathrm{~Hz}$, $1 \mathrm{H}, \mathrm{CH}_{2} \mathrm{OSi}$ ), 4.16 (d, $\left.J=4.9 \mathrm{~Hz}, 2 \mathrm{H}, \mathrm{H}-4\right), 4.27$ (dd, $J=3.5$, $\left.11.0 \mathrm{~Hz}, 1 \mathrm{H}, \mathrm{CH}_{2} \mathrm{OSi}\right), 4.54-4,59(\mathrm{~m}, 1 \mathrm{H}, \mathrm{H}-1), 4.69(\mathrm{~d}, J=6.9 \mathrm{~Hz}$, $\left.1 \mathrm{H}, \mathrm{H}-4^{\prime}\right), 4.73\left(\mathrm{dd}, J=5.2,6.9 \mathrm{~Hz}, 1 \mathrm{H}, \mathrm{H}-3^{\prime}\right), 5.93(\mathrm{tdd}, J=1.2$, $5.9,15.6 \mathrm{~Hz}, 1 \mathrm{H}, \mathrm{H}-2), 5.99(\mathrm{dt}, J=5.0,15.6 \mathrm{~Hz}, 1 \mathrm{H}, \mathrm{H}-3), 7.01(\mathrm{~s}$, $1 \mathrm{H}, \mathrm{N}-\underline{\mathrm{OH}}$ ), 7.37-7.44 (m, 6H, H-Ph), 7.62-7.69 (m, 4H, H-Ph). ${ }^{13} \mathrm{C}$ NMR $\left(150 \mathrm{MHz}, \mathrm{CDCl}_{3}\right) \delta(\mathrm{ppm}) 19.2\left[\mathrm{SiC}\left(\mathrm{CH}_{3}\right)_{3}\right], 24.0$ $\left(\mathrm{CH}_{3}\right), 25.8\left(\mathrm{CH}_{3}\right), 27.0\left[\mathrm{SiC}\left(\mathrm{CH}_{3}\right)_{3}\right], 60.1\left(\mathrm{C}-1^{\prime}\right), 63.2(\mathrm{C}-6), 69.3$ (C-5), 70.7 (C-2), 70.9 (C-4'), 78.3 (C-3), 79.2 (C-4), 111.1 $\left[\mathrm{C}\left(\mathrm{CH}_{3}\right)_{2}\right], 127.8(\mathrm{CH}, \mathrm{Ph}), 127.9(\mathrm{CH}, \mathrm{Ph}), 129.9(\mathrm{CH}, \mathrm{Ph}), 130.0$ (CH, Ph), $131.2\left(\mathrm{C}-2^{\prime}\right), 131.9\left(\mathrm{C}-3^{\prime}\right), 132.9(\mathrm{C}, \mathrm{Ph}), 133.0(\mathrm{C}, \mathrm{Ph})$, $135.7(\mathrm{CH}, \mathrm{Ph}), 135.8(\mathrm{CH}, \mathrm{Ph})$. HRMS (ESI) $\mathrm{m} / \mathrm{z}$ : for $\mathrm{C}_{28} \mathrm{H}_{40} \mathrm{NO}_{6} \mathrm{Si}[\mathrm{M}+\mathrm{H}]^{+}$, calcd: 514.2620; found: 514.2621.

$(R, E)-1-\{(2 R, 3 S, 4 R, 5 R)-5-[($ tert-Butyldiphenylsilyl)oxymethyl]3,4-isopropylidenedioxypyrrolidin-2-yl\}but-2-ene-1,4-diol

Isoxazolidine $13(850 \mathrm{mg}, 1.65 \mathrm{mmol}, 1$ equiv.) was dissolved in aqueous $\mathrm{AcOH}\left(11 \mathrm{~mL}, \mathrm{AcOH} / \mathrm{H}_{2} \mathrm{O}, 1: 1\right)$. Zinc powder $(2.16 \mathrm{~g}$, $33 \mathrm{mmol}, 20$ equiv.) and the reaction mixture was vigorously stirred at room temperature for $30 \mathrm{~min}$. The progress of the reaction was monitored by TLC (EtOAc). After observing the complete disappearance of the starting material, zinc was removed by filtration through filter paper under vacuum and washed with $\mathrm{CH}_{2} \mathrm{Cl}_{2}(200 \mathrm{~mL})$. Saturated aqueous $\mathrm{NaHCO}_{3}$ was slowly added to the stirring solution until the $\mathrm{pH}$ was neutral. The organic layer was separated, and the aqueous layer was extracted with $\mathrm{CH}_{2} \mathrm{Cl}_{2}(3 \times 100 \mathrm{~mL})$. The combined organic layers were dried over $\mathrm{MgSO}_{4}$, filtered, and concentrated under reduced pressure. The residue was purified by FCC $\left(\mathrm{CH}_{2} \mathrm{Cl}_{2} /\right.$ $\mathrm{MeOH} 97: 3)$ to give alcohol 4 (665 mg, $1.34 \mathrm{mmol}, 81 \%)$ as a yellowish oil.

$R_{\mathrm{f}}=0.27\left(\mathrm{CH}_{2} \mathrm{Cl}_{2} / \mathrm{MeOH} 95: 5\right),[\alpha]_{\mathrm{D}}^{25}=-8.49$ (c 1.07, $\mathrm{CHCl}_{3}$ ). IR (ATR) $\nu_{\max }: 3350 ; 2931 ; 2858 ; 1427 ; 1208 ; 1105 ; 1043$; $742 ; 700 ; 613 ; 502 \mathrm{~cm}^{-1} .{ }^{1} \mathrm{H}$ NMR $\left(600 \mathrm{MHz}, \mathrm{CDCl}_{3}\right) \delta(\mathrm{ppm}) 1$. 05 (s, 9H, Sit-Bu), 1.31 (s, 3H, $\left.\mathrm{CH}_{3}\right), 1.50\left(\mathrm{~s}, 3 \mathrm{H}, \mathrm{CH}_{3}\right), 2.35$ (bs, $3 \mathrm{H}, \mathrm{C} 1-\underline{\mathrm{OH}}, \mathrm{C} 4-\mathrm{OH}, \mathrm{NH}), 3.10\left(\mathrm{dd}, J=4.4,5.8 \mathrm{~Hz}, 1 \mathrm{H}, \mathrm{H}-2^{\prime}\right)$, $3.36\left(\mathrm{t}, J=5.9 \mathrm{~Hz}, 1 \mathrm{H}, \mathrm{H}-5^{\prime}\right), 3.59(\mathrm{dd}, J=6.2,10.5 \mathrm{~Hz}, 1 \mathrm{H}$, $\mathrm{CH}_{2} \mathrm{OSi}$ ), $3.64\left(\mathrm{dd}, J=5.6,10.5 \mathrm{~Hz}, 1 \mathrm{H}, \mathrm{CH}_{2} \mathrm{OSi}\right), 4.15(\mathrm{~d}, J=$ $5.2 \mathrm{~Hz}, 2 \mathrm{H}, \mathrm{H}-4), 4.33(\mathrm{t}, J=6.0 \mathrm{~Hz}, 1 \mathrm{H}, \mathrm{H}-1), 4.67(\mathrm{~d}, J=5.8 \mathrm{~Hz}$, $\left.1 \mathrm{H}, \mathrm{H}-4^{\prime}\right), 4.70\left(\mathrm{dd}, J=4.4,5.8 \mathrm{~Hz}, 1 \mathrm{H}, \mathrm{H}-3^{\prime}\right), 5.84(\mathrm{tdd}, J=1.5$, $6.5,15.6 \mathrm{~Hz}, 1 \mathrm{H}, \mathrm{H}-2), 5.94(\mathrm{dtd}, J=1.0,5.2,15.6 \mathrm{~Hz}, 1 \mathrm{H}, \mathrm{H}-3)$, 7.37-7.45 (m, 6H, H-Ph), 7.62-7.66 (m, 4H, H-Ph). ${ }^{13} \mathrm{C} \mathrm{NMR} \mathrm{(150}$ $\left.\mathrm{MHz}, \mathrm{CDCl}_{3}\right) \delta(\mathrm{ppm}) 19.3\left[\mathrm{SiC}\left(\mathrm{CH}_{3}\right)_{3}\right], 23.9\left(\mathrm{CH}_{3}\right), 26.1\left(\mathrm{CH}_{3}\right)$, $27.0\left[\mathrm{SiC}\left(\mathrm{CH}_{3}\right)_{3}\right], 62.9\left(\mathrm{C}-1^{\prime}\right), 64.7$ (C-5), 64.9 (C-6), $65.1(\mathrm{C}-2)$, $72.1\left(\mathrm{C}-4^{\prime}\right), 82.5(\mathrm{C}-3), 83.9(\mathrm{C}-4), 111.5\left[\mathrm{C}\left(\mathrm{CH}_{3}\right)_{2}\right], 127.9(2 \times$ $\mathrm{CH}, \mathrm{Ph}), 130.0(2 \times \mathrm{CH}, \mathrm{Ph}), 131.5\left(\mathrm{C}-2^{\prime}\right), 131.7\left(\mathrm{C}-3^{\prime}\right), 133.2(2 \times$ C, $\mathrm{Ph}$ ), $135.7(2 \times \mathrm{CH}, \mathrm{Ph})$. HRMS (ESI) $m / z$ : for $\mathrm{C}_{28} \mathrm{H}_{40} \mathrm{NO}_{5} \mathrm{Si}[\mathrm{M}+$ $\mathrm{H}]^{+}$, calcd: 498.2671 ; found: 498.2676 .

$(3 \mathrm{a} R, 4 R, 8 S, 8 \mathrm{a} R, 8 \mathrm{~b} S)-4$-[(tert-Butyldiphenylsilyl)oxymethyl]6-(hydroxymethyl)-7-iodo-2,2-dimethylhexahydro-3a $H$-[1,3]dioxolo[4,5-a]pyrrolizin-8-ol $(14,15)$. To a stirred solution of isoxazolidine 4 (650 mg, $1.31 \mathrm{mmol}, 1$ equiv.) in anhydrous EtOAc $(13 \mathrm{~mL})$ was at $-20^{\circ} \mathrm{C}$ under $\mathrm{Ar}$ atmosphere added anhydrous $\mathrm{K}_{2} \mathrm{CO}_{3}(1.81 \mathrm{~g}, 13.1 \mathrm{mmol}, 10$ equiv.) and iodine $(1.0 \mathrm{~g}$, $3.94 \mathrm{mmol}, 3$ equiv.). The reaction mixture was stirred for 1 hour and after observing a complete disappearance of the starting material with TLC (EtOAc), saturated aqueous solution of $\mathrm{Na}_{2} \mathrm{~S}_{2} \mathrm{O}_{3} \cdot 5 \mathrm{H}_{2} \mathrm{O}(20 \mathrm{~mL})$ was added. The reaction mixture was vigorously stirred for 10 minutes until its colour completely changed from brown to white. The aqueous layer was extracted with EtOAc $(4 \times 20 \mathrm{~mL})$. The combined organic layers were dried over $\mathrm{MgSO}_{4}$, filtered, and concentrated under reduced pressure to give the crude mixture of iodo-pyrrolizidines $\mathbf{1 4}$ and 15, which was used directly in next reaction without further purification.

With the aim to completely characterize the new compounds, a sample of the mixture was subjected to preparative TLC $\left(\mathrm{CH}_{2} \mathrm{Cl}_{2} / \mathrm{MeOH} 9: 1\right)$ to give two pure isomers 14 and 15 as yellowish solids.

Data for $(6 S, 7 S)$-14. $R_{\mathrm{f}}=0.21(n$-hexane/EtOAc $7: 3), \mathrm{mp}=51$ $54{ }^{\circ} \mathrm{C},[\alpha]_{\mathrm{D}}^{25}=-124.7\left(c 1.00, \mathrm{CHCl}_{3}\right)$. IR (ATR) $\nu_{\text {max }}: 3435 ; 2930$; 2856; 1427; 1207; 1111; 1083; 823; 740; 700; 613; $502 \mathrm{~cm}^{-1} .{ }^{1} \mathrm{H}$ NMR $\left(600 \mathrm{MHz}, \mathrm{CDCl}_{3}\right) \delta(\mathrm{ppm}) 1.06(\mathrm{~s}, 9 \mathrm{H}, \mathrm{Sit}-\mathrm{Bu}), 1.28(\mathrm{~s}, 3 \mathrm{H}$, $\left.\mathrm{CH}_{3}\right), 1.50\left(\mathrm{~s}, 3 \mathrm{H}, \mathrm{CH}_{3}\right), 2.09$ (bs, $\left.1 \mathrm{H}, \mathrm{OH}\right), 2.98$ (bs, $\left.1 \mathrm{H}, \mathrm{OH}\right)$, 3.48-3.54 (m, 2H, H-3, H- $8_{\mathrm{a}}$ ), 3.56 (dd, $J=5.6,10.1 \mathrm{~Hz}, 1 \mathrm{H}, \mathrm{H}-$ $8 \mathrm{~b}), 3.64(\mathrm{dd}, J=3.1,9.6 \mathrm{~Hz}, 1 \mathrm{H}, \mathrm{H}-5), 3.70(\mathrm{~d}, J=13.5 \mathrm{~Hz}, 1 \mathrm{H}, \mathrm{H}-$ $\left.9_{\mathrm{a}}\right), 3.76(\mathrm{~d}, J=5.1 \mathrm{~Hz}, 1 \mathrm{H}, \mathrm{H}-7 \mathrm{a}), 3.85\left(\mathrm{~d}, J=13.0 \mathrm{~Hz}, 1 \mathrm{H}, \mathrm{H}-9_{\mathrm{b}}\right)$, $4.09(\mathrm{~d}, J=4.3 \mathrm{~Hz}, 1 \mathrm{H}, \mathrm{H}-7), 4.40(\mathrm{dd}, J=4.2,9.7 \mathrm{~Hz}, 1 \mathrm{H}, \mathrm{H}-6)$, $4.59(\mathrm{t}, J=5.5 \mathrm{~Hz}, 1 \mathrm{H}, \mathrm{H}-1), 4.66(\mathrm{~d}, J=5.8 \mathrm{~Hz}, 1 \mathrm{H}, \mathrm{H}-2), 7.39-$ $7.45(\mathrm{~m}, 6 \mathrm{H}, \mathrm{H}-\mathrm{Ph}), 7.67-7.69(\mathrm{~m}, 4 \mathrm{H}, \mathrm{H}-\mathrm{Ph}) .{ }^{13} \mathrm{C}$ NMR $(150$ $\left.\mathrm{MHz}, \mathrm{CDCl}_{3}\right) \delta(\mathrm{ppm}) 19.2\left[\mathrm{SiC}\left(\mathrm{CH}_{3}\right)_{3}\right], 23.4\left(\mathrm{CH}_{3}\right), 25.0\left(\mathrm{CH}_{3}\right)$, $27.0\left[\mathrm{SiC}\left(\mathrm{CH}_{3}\right)_{3}\right], 35.6$ (C-6), 58.1 (C-9), 64.7 (C-3), 66.1 (C-8), 68.5 (C-5), 71.5 (C-7a), 72.0 (C-7), 80.9 (C-1), 85.3 (C-2), 112.4 
$\left[\mathrm{C}\left(\mathrm{CH}_{3}\right)_{2}\right], 128.0(2 \times \mathrm{CH}, \mathrm{Ph}), 130.0(2 \times \mathrm{CH}, \mathrm{Ph}), 133.2(2 \times \mathrm{C}$, $\mathrm{Ph}), 135.8$ ( $2 \times \mathrm{CH}, \mathrm{Ph}$ ). HRMS (ESI) $\mathrm{m} / z$ : for $\mathrm{C}_{28} \mathrm{H}_{39} \mathrm{INO}_{5} \mathrm{Si}[\mathrm{M}+$ $\mathrm{H}]^{+}$, calcd: 624.1637 ; found: 624.1640 .

Data for $(6 R, 7 R)-15 . R_{\mathrm{f}}=0.17(n$-hexane/EtOAc $7: 3), \mathrm{mp}=$ $45-48{ }^{\circ} \mathrm{C},[\alpha]_{\mathrm{D}}^{25}=-32.9\left(c 1.01, \mathrm{CHCl}_{3}\right)$. IR (ATR) $\nu_{\max }: 3427$; 2931; 2857; 1427; 1209; 1105; 1063; 823; 739; 700; 613; $501 \mathrm{~cm}^{-1}$. ${ }^{1} \mathrm{H}$ NMR (600 MHz, CDCl $) \delta(\mathrm{ppm}) 1.06$ (s, 9H, Sit-Bu), $1.30(\mathrm{~s}$, $\left.3 \mathrm{H}, \mathrm{CH}_{3}\right), 1.52\left(\mathrm{~s}, 3 \mathrm{H}, \mathrm{CH}_{3}\right), 2.33(\mathrm{bs}, 1 \mathrm{H}, \mathrm{OH}), 3.29(\mathrm{t}, J=5.6 \mathrm{~Hz}$, $1 \mathrm{H}, \mathrm{H}-3), 3.46-3.49$ (m, 2H, H-8 a,b), 3.51 (dt, $J=2.3,10.2 \mathrm{~Hz}, 1 \mathrm{H}$, H-5), 3.57-3.60 (m, 3H, H-7a, H-9a,b), 4.17 (dd, $J=8.3,10.2 \mathrm{~Hz}$, $1 \mathrm{H}, \mathrm{H}-6), 4.59$ (dd, $J=1.0,5.7 \mathrm{~Hz}, 1 \mathrm{H}, \mathrm{H}-2), 4.71$ (t, $J=5.6 \mathrm{~Hz}$, $1 \mathrm{H}, \mathrm{H}-1), 4.86$ (dd, $J=4.8,8.3 \mathrm{~Hz}, 1 \mathrm{H}, \mathrm{H}-7), 7.39-7.46$ (m, 6H, H$\mathrm{Ph}), 7.66-7.68$ (m, 4H, H-Ph). ${ }^{13} \mathrm{C}$ NMR (150 MHz, $\mathrm{CDCl}_{3}$ ) $\delta(\mathrm{ppm}) \quad 19.2\left[\mathrm{SiC}\left(\mathrm{CH}_{3}\right)_{3}\right], \quad 24.0 \quad\left(\mathrm{CH}_{3}\right), 26.8 \quad\left(\mathrm{CH}_{3}\right), \quad 27.0$ $\left[\mathrm{SiC}\left(\mathrm{CH}_{3}\right)_{3}\right], 31.1(\mathrm{C}-6), 58.9(\mathrm{C}-9), 66.0(\mathrm{C}-8), 67.6(\mathrm{C}-3), 72.8(\mathrm{C}-$ 5), 73.4 (C-7a), 79.7 (C-7), 81.7 (C-1), 85.3 (C-2), $112.6\left[\mathrm{C}\left(\mathrm{CH}_{3}\right)_{2}\right]$, $128.0(2 \times \mathrm{CH}, \mathrm{Ph}), 130.0(2 \times \mathrm{CH}, \mathrm{Ph}), 132.9(2 \times \mathrm{C}, \mathrm{Ph}), 135.7$ $(2 \times \mathrm{CH}, \mathrm{Ph})$. HRMS (ESI) $m / z$ : for $\mathrm{C}_{28} \mathrm{H}_{39} \mathrm{INO}_{5} \mathrm{Si}[\mathrm{M}+\mathrm{H}]^{+}$, calcd: 624.1637; found: 624.1640 .

$(3 \mathrm{a} R, 4 R, 8 R, 8 \mathrm{a} R, 8 \mathrm{bS})-4$-[(tert-Butyldiphenylsilyl)oxymethyl]6-(hydroxymethyl)-2,2-dimethylhexahydro-3a $\mathrm{H}$-[1,3]dioxolo[4,5a]pyrrolizin-8-ol $(\mathbf{1 6}, \mathbf{1 7})$. Reaction flask with magnetic stirrer and $\mathrm{InCl}_{3}$ (580 mg, $2.62 \mathrm{mmol}, 2$ equiv.) was sealed with a rubber septum, evacuated, and filled with Ar. Under stream of Ar, first portion of anhydrous THF $(6.5 \mathrm{~mL})$ was added to the flask and the mixture was cooled down to $0{ }^{\circ} \mathrm{C}$ in an ice/water bath. A second reaction flask was filled with the mixture of iodo-pyrrolizidines 14 and 15 (1.31 mmol, 1 equiv.) from previous reaction. The flask was sealed with a rubber septum, evacuated, and filled with Ar. The starting material was gradually dissolved in a second portion of anhydrous THF $(6.5 \mathrm{~mL})$ under stream of $\mathrm{Ar}$ and subsequently added to the stirring suspension of $\mathrm{InCl}_{3}$ in THF. Solution of DIBAL-H ( $1 \mathrm{M}$ in hexane, $13.1 \mathrm{~mL}, 13.1 \mathrm{mmol}, 10$ equiv.) was slowly added to the cooled reaction mixture, which was stirred for $24 \mathrm{~h}$ at $0{ }^{\circ} \mathrm{C}$. The reaction progress was monitored by TLC (EtOAc). After complete consumption of the starting material, EtOAc $(30 \mathrm{~mL})$ and saturated aqueous solution of potassium sodium tartrate $(30 \mathrm{~mL})$ were added, and the resulting slurry was vigorously stirred for $2 \mathrm{~h}$ at room temperature until two clear phases appeared. The organic layer was separated, and the aqueous layer was extracted with EtOAc $(3 \times 50 \mathrm{~mL})$. The combined organic layers were dried over $\mathrm{MgSO}_{4}$, filtered, and concentrated under reduced pressure. The residue was purified by FCC (hexanes/EtOAc $1: 3$ ) to give two pure pyrrolizidines 16 (195 mg, $0.39 \mathrm{mmol}, 30 \%$ after two steps) and 17 (165 mg, $0.33 \mathrm{mmol}$, $25 \%$ after two steps) as yellowish oils.

Data for $(6 S)$-16. $R_{\mathrm{f}}=0.21$ ( $n$-hexane/EtOAc $\left.1: 9\right),[\alpha]_{\mathrm{D}}^{25}=+1.04$ (c $1.00, \mathrm{CHCl}_{3}$ ). IR (ATR) $\nu_{\max }: 3402 ; 2928 ; 2854 ; 1430 ; 1380$; 1206; 1106; 1047; 703; 617; $506 \mathrm{~cm}^{-1}$. ${ }^{1} \mathrm{H}$ NMR $(600 \mathrm{MHz}$, $\left.\mathrm{CD}_{3} \mathrm{OD}\right) \delta(\mathrm{ppm}) 1.07$ (s, 9H, Sit-Bu), 1.29 (s, 3H, $\left.\mathrm{CH}_{3}\right), 1.47$ (s, $\left.3 \mathrm{H}, \mathrm{CH}_{3}\right), 1.83-1.88\left(\mathrm{~m}, 1 \mathrm{H}, \mathrm{H}-6_{\mathrm{a}}\right), 1.92-1.98\left(\mathrm{~m}, 1 \mathrm{H}, \mathrm{H}-6_{\mathrm{b}}\right)$, 3.48-3.52 (m, 3H, H-5, H-3, H-9a), 3.55 (dd, $J=3.3,5.2 \mathrm{~Hz}, 1 \mathrm{H}$, $\mathrm{H}-7 \mathrm{a}), 3.57$ (dd, $J=6.7,10.2 \mathrm{~Hz}, 1 \mathrm{H}, \mathrm{H}-8_{\mathrm{a}}$ ), 3.60-3.64 (m, 1H, H$\left.9_{\mathrm{b}}\right), 3.70\left(\mathrm{dd}, J=4.9,10.2 \mathrm{~Hz}, 1 \mathrm{H}, \mathrm{H}-8_{\mathrm{b}}\right), 4.36(\mathrm{ddd}, J=3.4,4.2$, $6.1 \mathrm{~Hz}, 1 \mathrm{H}, \mathrm{H}-7$ ), 4.59 (pseudo t, $J=5.4,5.7 \mathrm{~Hz}, 1 \mathrm{H}, \mathrm{H}-1$ ), 4.70 (dd, $J=1.5,5.9 \mathrm{~Hz}, 1 \mathrm{H}, \mathrm{H}-2$ ), 7.39-7.46 (m, 6H, H-Ph), 7.69-7.72 (m, 4H, H-Ph). ${ }^{13} \mathrm{C}$ NMR (150 MHz, CD $\left.{ }_{3} \mathrm{OD}\right) \delta(\mathrm{ppm}) 20.0$ [SiC $\left.\left(\mathrm{CH}_{3}\right)_{3}\right], 24.3\left(\mathrm{CH}_{3}\right), 26.1\left(\mathrm{CH}_{3}\right), 27.4\left[\mathrm{SiC}\left(\mathrm{CH}_{3}\right)_{3}\right], 40.2(\mathrm{C}-6)$, 61.8 (C-7a), 64.0 (C-9), 64.8 (C-5), 66.6 (C-8), 70.6 (C-7), 76.9 (C-3), 81.2 (C-2), $87.3(\mathrm{C}-1), 113.1\left[\underline{\mathrm{C}}\left(\mathrm{CH}_{3}\right)_{2}\right], 128.8(\mathrm{CH}, \mathrm{Ph}), 128.9(\mathrm{CH}$, $\mathrm{Ph}), 130.9$ (CH, Ph), 131.0 (CH, Ph), 134.6 (2× C, Ph), $136.8(2 \times$ $\mathrm{CH}, \mathrm{Ph}$ ). HRMS (ESI) $m / z$ : for $\mathrm{C}_{28} \mathrm{H}_{40} \mathrm{NO}_{5} \mathrm{Si}[\mathrm{M}+\mathrm{H}]^{+}$, calcd: 498.2671; found: 498.2673.

Data for $(6 R)-17 . R_{\mathrm{f}}=0.37(n$-hexane/EtOAc $1: 9),[\alpha]_{\mathrm{D}}^{25}=$ +2.13 ( c 1.00, $\mathrm{CHCl}_{3}$ ). IR (ATR) $\nu_{\text {max }}: 3399 ; 2934 ; 2858 ; 1427$; $1374 ; 1206 ; 1112 ; 1041 ; 829 ; 741 ; 706 ; 618 ; 509 \mathrm{~cm}^{-1} .{ }^{1} \mathrm{H}$ NMR $\left(600 \mathrm{MHz}, \mathrm{CD}_{3} \mathrm{OD}\right) \delta(\mathrm{ppm}) 1.06(\mathrm{~s}, 9 \mathrm{H}, \mathrm{Si} t-\mathrm{Bu}), 1.27\left(\mathrm{~s}, 3 \mathrm{H}, \mathrm{CH}_{3}\right)$, $1.45\left(\mathrm{~s}, 3 \mathrm{H}, \mathrm{CH}_{3}\right), 1.60$ (ddd, $J=4.8,7.4,13.0 \mathrm{~Hz}, 1 \mathrm{H}, \mathrm{H}-6_{\mathrm{a}}$ ), 2.44 (dt, $\left.J=7.4,13.0 \mathrm{~Hz}, 1 \mathrm{H}, \mathrm{H}-6_{\mathrm{b}}\right), 3.32-3.44(\mathrm{~m}, 4 \mathrm{H}, \mathrm{H}-3, \mathrm{H}-5, \mathrm{H}-$ 9a,b) 3.51-3.54 (m, 2H, H-7a, H-8a), $3.64(\mathrm{dd}, J=5.7,10.4 \mathrm{~Hz}$, $1 \mathrm{H}, \mathrm{H}-8_{\mathrm{b}}$ ), 4.56 (ddd, $J=2.4,4.8,7.2 \mathrm{~Hz}, 1 \mathrm{H}, \mathrm{H}-7$ ), 4.63 (pseudo $\mathrm{t}, J=5.1,5.7 \mathrm{~Hz}, 1 \mathrm{H}, \mathrm{H}-1), 4.68(\mathrm{dd}, J=1.3,5.7 \mathrm{~Hz}, 1 \mathrm{H}, \mathrm{H}-2)$, 7.40-7.46 (m, 6H, H-Ph), 7.70-7.73 (m, 4H, H-Ph). ${ }^{13} \mathrm{C}$ NMR (150 MHz, CD $\left.{ }_{3} \mathrm{OD}\right) \delta(\mathrm{ppm}) 19.9$ [SiC $\left.\left(\mathrm{CH}_{3}\right)_{3}\right], 23.9\left(\mathrm{CH}_{3}\right), 26.9$ $\left(\mathrm{CH}_{3}\right), 27.4\left[\mathrm{SiC}\left(\mathrm{CH}_{3}\right)_{3}\right], 40.3(\mathrm{C}-6), 67.1(\mathrm{C}-8), 67.2$ (C-9), 68.2 (C5), 71.9 (C-3), 72.0 (C-7), 77.7 (C-7a), 83.3 (C-2), 87.1 (C-1), 113.0 $\left[\underline{\mathrm{C}}\left(\mathrm{CH}_{3}\right)_{2}\right], 128.8(\mathrm{CH}, \mathrm{Ph}), 128.9(\mathrm{CH}, \mathrm{Ph}), 130.9(\mathrm{CH}, \mathrm{Ph}), 131.0$ (CH, Ph), $134.5(2 \times \mathrm{C}, \mathrm{Ph}), 137.8(2 \times \mathrm{CH}, \mathrm{Ph}) . \mathrm{HRMS}(\mathrm{ESI}) \mathrm{m} / z$ : for $\mathrm{C}_{28} \mathrm{H}_{40} \mathrm{NO}_{5} \mathrm{Si}[\mathrm{M}+\mathrm{H}]^{+}$, calcd: 498.2671; found: 498.2672 .

$\{(3 \mathrm{a} R, 4 R, 6 S, 8 R, 8 \mathrm{a} R, 8 \mathrm{~b} S)-8$-Hydroxy-2,2-dimethylhexahydro$3 \mathrm{a} H$-[1,3]dioxolo[4,5-a]pyrrolizine-4,6-diyl\}dimethanol (18). Pyrrolizidine 16 (195 mg, $0.39 \mathrm{mmol}, 1$ equiv.) was dissolved in methanol (1.95 mL) and CsF (296 mg, $1.95 \mathrm{mmol}, 5$ equiv.) was added to the solution. The reaction mixture was stirred at $50{ }^{\circ} \mathrm{C}$ for $48 \mathrm{~h}$. The progress of the reaction was monitored by TLC $\left(\mathrm{CH}_{2} \mathrm{Cl}_{2} / \mathrm{MeOH} 9: 1\right)$. After full disappearance of the starting pyrrolizidine $\mathrm{MeOH}$ was removed under reduced pressure. The residue was purified by $\mathrm{FCC}\left(\mathrm{CH}_{2} \mathrm{Cl}_{2} / \mathrm{MeOH} 4: 1\right)$ to give pyrrolizidine $18(85 \mathrm{mg}, 0.33 \mathrm{mmol}, 85 \%)$ as a yellowish oil.

$R_{\mathrm{f}}=0.16\left(\mathrm{CH}_{2} \mathrm{Cl}_{2} / \mathrm{MeOH} 4: 1\right),[\alpha]_{\mathrm{D}}^{25}=+206.3\left(c 0.90, \mathrm{CHCl}_{3}\right)$. IR (ATR) $\nu_{\text {max }}: 3311 ; 2981 ; 2937 ; 2360 ; 1383 ; 1206 ; 1165 ; 1024$; 859; $512 \mathrm{~cm}^{-1} .{ }^{1} \mathrm{H}$ NMR (600 MHz, CD $\mathrm{CD}_{3} \mathrm{OD}(\mathrm{ppm}) 1.32(\mathrm{~s}, 3 \mathrm{H}$, $\mathrm{CH}_{3}$ ), 1.49 (s, 3H, $\mathrm{CH}_{3}$ ), 1.90 (ddd, $J=2.8,5.8,12.9 \mathrm{~Hz}, 1 \mathrm{H}, \mathrm{H}-$ $\left.6_{\mathrm{a}}\right), 2.00\left(\mathrm{ddd}, J=5.3,9.2,12.9 \mathrm{~Hz}, 1 \mathrm{H}, \mathrm{H}-6_{\mathrm{b}}\right), 3.60-3.65(\mathrm{~m}, 2 \mathrm{H}$, $\mathrm{H}-9_{\mathrm{a}, \mathrm{b}}$ ), 3.72-3.81 (m, 5H, H-3, H-5, H-7a, H-8 $\left.\mathrm{a}, \mathrm{b}\right), 4.44$ (dt, $J=$ 2.6, $5.3 \mathrm{~Hz}, 1 \mathrm{H}, \mathrm{H}-7), 4.72(\mathrm{dd}, J=2.2,6.0 \mathrm{~Hz}, 1 \mathrm{H}, \mathrm{H}-2), 4.76(\mathrm{t}, J$ $=5.8 \mathrm{~Hz}, 1 \mathrm{H}, \mathrm{H}-1) .{ }^{13} \mathrm{C} \mathrm{NMR}\left(150 \mathrm{MHz}, \mathrm{CD}_{3} \mathrm{OD}\right) \delta(\mathrm{ppm}) 24.3$ $\left(\mathrm{CH}_{3}\right), 26.2\left(\mathrm{CH}_{3}\right), 39.1(\mathrm{C}-6), 62.7(\mathrm{C}-8), 63.2(\mathrm{C}-9), 64.2(\mathrm{C}-3)$, 66.1 (C-5), 70.8 (C-5), 78.2 (C-7a), 80.7 (C-1), 86.2 (C-2), 113.4 $\left[\mathrm{C}\left(\mathrm{CH}_{3}\right)_{2}\right]$. HRMS (ESI) $m / z$ : for $\mathrm{C}_{12} \mathrm{H}_{22} \mathrm{NO}_{5}[\mathrm{M}+\mathrm{H}]^{+}$, calcd: 260.1493; found: 260.1489 .

$\{(3 \mathrm{a} R, 4 R, 6 R, 8 R, 8 \mathrm{a} R, 8 \mathrm{~b} S)-8$-Hydroxy-2,2-dimethylhexahydro$3 \mathrm{a} H$-[1,3]dioxolo[4,5-a]pyrrolizine-4,6-diyl\}dimethanol (19). Pyrrolizidine 17 (165 mg, $0.33 \mathrm{mmol}, 1$ equiv.) was dissolved in methanol (1.65 mL) and CsF (251 mg, $1.65 \mathrm{mmol}, 5$ equiv.) was added to the solution. The reaction mixture was stirred at $50{ }^{\circ} \mathrm{C}$ for $96 \mathrm{~h}$. The progress of the reaction was monitored by TLC $\left(\mathrm{CH}_{2} \mathrm{Cl}_{2} / \mathrm{MeOH} 9: 1\right)$. After full disappearance of the starting pyrrolizidine $\mathrm{MeOH}$ was removed under reduced pressure. The residue was purified by $\mathrm{FCC}\left(\mathrm{CH}_{2} \mathrm{Cl}_{2} / \mathrm{MeOH} 4: 1\right)$ to give pyrrolizidine 19 (80 $\mathrm{mg}, 0.31 \mathrm{mmol}, 94 \%)$ as a yellowish oil.

$R_{\mathrm{f}}=0.34\left(\mathrm{CH}_{2} \mathrm{Cl}_{2} / \mathrm{MeOH} 4: 1\right),[\alpha]_{\mathrm{D}}^{25}=+1.78\left(c 1.00, \mathrm{CHCl}_{3}\right)$. IR (ATR) $\nu_{\text {max }}: 3344 ; 2931 ; 2860 ; 1430 ; 1212 ; 1109 ; 1074 ; 1032$; 
$700 ; 618 ; 505 \mathrm{~cm}^{-1} .{ }^{1} \mathrm{H}$ NMR $\left(600 \mathrm{MHz}, \mathrm{CD}_{3} \mathrm{OD}\right) \delta(\mathrm{ppm}) 1.30(\mathrm{~s}$, $\left.3 \mathrm{H}, \mathrm{CH}_{3}\right), 1.46\left(\mathrm{~s}, 3 \mathrm{H}, \mathrm{CH}_{3}\right), 1.63$ (ddd, $J=4.6,7.3,13.1 \mathrm{~Hz}, 1 \mathrm{H}$, $\mathrm{H}-6_{\mathrm{a}}$ ), 2.45 (dt, $\left.J=7.6,13.1 \mathrm{~Hz}, 1 \mathrm{H}, \mathrm{H}-6_{\mathrm{b}}\right), 3.28-3.30(\mathrm{~m}, 1 \mathrm{H}, \mathrm{H}-$ 3), $3.39(\mathrm{tt}, J=5.3,7.7 \mathrm{~Hz}, 1 \mathrm{H}, \mathrm{H}-5), 3.43(\mathrm{dd}, J=7.2,11.0 \mathrm{~Hz}$, $1 \mathrm{H}, \mathrm{H}-8_{\mathrm{a}}$ ), 3.48 (dd, $J=5.8,11.0 \mathrm{~Hz}, 1 \mathrm{H}, \mathrm{H}-8_{\mathrm{b}}$ ), $3.50(\mathrm{~d}, J=$ $\left.5.3 \mathrm{~Hz}, 2 \mathrm{H}, \mathrm{H}-9_{\mathrm{a}, \mathrm{b}}\right), 3.55$ (dd, $\left.J=2.3,4.8 \mathrm{~Hz}, 1 \mathrm{H}, \mathrm{H}-7 \mathrm{a}\right), 4.57$ (ddd, $J=2.4,4.6,7.1 \mathrm{~Hz}, 1 \mathrm{H}, \mathrm{H}-7), 4.60(\mathrm{dd}, J=1.7,5.7 \mathrm{~Hz}, 1 \mathrm{H}$, $\mathrm{H}-2$ ), 4.70 (pseudo t, $J=5.2,5.4 \mathrm{~Hz}, 1 \mathrm{H}, \mathrm{H}-1) .{ }^{13} \mathrm{C}$ NMR $(150$ $\left.\mathrm{MHz}, \mathrm{CD}_{3} \mathrm{OD}\right) \delta(\mathrm{ppm}) 24.0\left(\mathrm{CH}_{3}\right), 26.9\left(\mathrm{CH}_{3}\right), 39.9(\mathrm{C}-6), 63.9(\mathrm{C}-$ 8), 66.6 (C-9), 68.5 (C-5), 72.0 (C-7), 72.6 (C-3), 77.2 (C-7a), 82.8 (C-1), 86.5 (C-2), $113.2 \quad\left[\mathrm{C}\left(\mathrm{CH}_{3}\right)_{2}\right]$. HRMS (ESI) $\mathrm{m} / \mathrm{z}$ : for $\mathrm{C}_{12} \mathrm{H}_{22} \mathrm{NO}_{5}[\mathrm{M}+\mathrm{H}]^{+}$, calcd: 260.1493; found: 260.1491 .

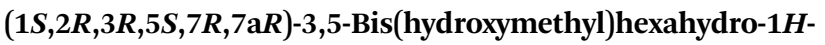
pyrrolizine-1,2,7-triol (2a). To a solution of pyrrolizidine 18 ( $85 \mathrm{mg}, 0.33 \mathrm{mmol}, 1$ equiv.) in $\mathrm{MeOH}(8 \mathrm{~mL})$ was added acidic ion exchange resin Dowex 50WX-8 $(850 \mathrm{mg}$, washed three times with $\mathrm{MeOH}$ before use). The suspension was vigorously stirred at room temperature for $1.5 \mathrm{~h}$ and then decanted. The progress of the reaction was monitored by TLC $\left(\mathrm{CH}_{2} \mathrm{Cl}_{2} / \mathrm{MeOH} 7: 3\right)$. Afterwards, the resin was well washed in the flask with $13 \%$ aqueous $\mathrm{NH}_{3}\left(26 \% \mathrm{NH}_{3} / \mathrm{H}_{2} \mathrm{O} 1: 1,5 \times 2 \mathrm{~mL}\right)$, and the combined liquids were concentrated under reduced pressure to give (+)-hyacinthacine $\mathrm{C}_{3}$ (2a, $\left.68 \mathrm{mg}, 0.31 \mathrm{mmol}, 94 \%\right)$ as a yellowish oil.

$R_{\mathrm{f}}=0.14\left(\mathrm{CH}_{2} \mathrm{Cl}_{2} / \mathrm{MeOH} / \mathrm{NH}_{3} 60: 35: 5\right),[\alpha]_{\mathrm{D}}^{22}=+9.30(c 0.3$, $\left.\mathrm{H}_{2} \mathrm{O}\right)$, [ref. $4:[\alpha]_{\mathrm{D}}^{22}=+8.80\left(c 0.3, \mathrm{H}_{2} \mathrm{O}\right)$, ref. $3:[\alpha]_{\mathrm{D}}=+3.5(c 0.23$, $\left.\left.\mathrm{H}_{2} \mathrm{O}\right)\right]$. IR (ATR) $\nu_{\text {max }}: 3282 ; 2931 ; 2878 ; 1409 ; 1342 ; 1124 ; 1024$; $600 ; 547 ; 477 \mathrm{~cm}^{-1} .{ }^{1} \mathrm{H}$ NMR $\left(600 \mathrm{MHz}, \mathrm{D}_{2} \mathrm{O}\right.$, TSP- $\left.d_{4}\right) \delta(\mathrm{ppm})$ $1.99\left(\mathrm{dt}, J=6.0,13.1 \mathrm{~Hz}, 1 \mathrm{H}, \mathrm{H}-6_{\mathrm{a}}\right), 2.16(\mathrm{dt}, J=6.6,13.2 \mathrm{~Hz}, 1 \mathrm{H}$, $\mathrm{H}-6_{\mathrm{b}}$ ), 3.33 (dt, $\left.J=4.7,8.3 \mathrm{~Hz}, 1 \mathrm{H}, \mathrm{H}-3\right), 3.54(\mathrm{t}, J=4.3 \mathrm{~Hz}, 1 \mathrm{H}$, H-7a), 3.60-3.64 (m, 1H, H-5), 3.69 (dd, $J=5.3,11.8 \mathrm{~Hz}, 1 \mathrm{H}, \mathrm{H}-$ 8 a), $3.81\left(\mathrm{dd}, J=6.0,12.5 \mathrm{~Hz}, 1 \mathrm{H}, \mathrm{H}-9_{\mathrm{a}}\right.$ ); $3.83(\mathrm{dd}, J=4.2$, $11.8 \mathrm{~Hz}, 1 \mathrm{H}, \mathrm{H}-8_{\mathrm{b}}$ ), 3.86 (dd, $J=4.4,12.5 \mathrm{~Hz}, 1 \mathrm{H}, \mathrm{H}-9_{\mathrm{b}}$ ), 4.05 (dd, $J=4.1,8.3 \mathrm{~Hz}, 1 \mathrm{H}, \mathrm{H}-2), 4.23(\mathrm{t}, J=4.3 \mathrm{~Hz}, 1 \mathrm{H}, \mathrm{H}-1), 4.63(\mathrm{td}, J=$ $4.2,5.8 \mathrm{~Hz}, 1 \mathrm{H}, \mathrm{H}-7) .{ }^{13} \mathrm{C} \mathrm{NMR}\left(150 \mathrm{MHz}, \mathrm{D}_{2} \mathrm{O}\right) \delta(\mathrm{ppm}) 40.1$ (C6), 63.1 (C-9), 64.4 (C-8), 64.5 (C-3), 64.8 (C-5), 71.2 (C-7), 72.7 (C1), 77.1 (C-2), 77.3 (C-7a). HRMS (ESI) $m / z$ : for $\mathrm{C}_{9} \mathrm{H}_{18} \mathrm{NO}_{5}[\mathrm{M}+$ $\mathrm{H}]^{+}$, calcd: 220.1180; found: 220.1180 .

$(1 S, 2 R, 3 R, 5 R, 7 R, 7 \mathrm{a} R)-3,5-\mathrm{Bis}(\mathrm{hydroxymethyl}) h e x a h y d r o-1 H$ pyrrolizine-1,2,7-triol (2b). To a solution of pyrrolizidine 19 ( $80 \mathrm{mg}, 0.31 \mathrm{mmol}, 1$ equiv.) in $\mathrm{MeOH}(8 \mathrm{~mL})$ was added acidic ion exchange resin Dowex 50WX-8 $(800 \mathrm{mg}$, washed three times with $\mathrm{MeOH}$ before use). The suspension was vigorously stirred at room temperature for $2 \mathrm{~h}$ and then decanted. The progress of the reaction was monitored by TLC $\left(\mathrm{CH}_{2} \mathrm{Cl}_{2} / \mathrm{MeOH} 7: 3\right)$. Afterwards, the resin was well washed in the flask with $13 \%$ aqueous $\mathrm{NH}_{3}\left(26 \% \mathrm{NH}_{3} / \mathrm{H}_{2} \mathrm{O} 1: 1,5 \times 2 \mathrm{~mL}\right)$, and the combined liquids were concentrated under reduced pressure to give (+)-5-epi-hyacinthacine $\mathrm{C}_{3}(2 \mathrm{~b}, 65 \mathrm{mg}, 0.29 \mathrm{mmol}, 95 \%)$ as a yellowish oil.

$R_{\mathrm{f}}=0.25\left(\mathrm{CH}_{2} \mathrm{Cl}_{2} / \mathrm{MeOH} / \mathrm{NH}_{3} 60: 35: 5\right),[\alpha]_{\mathrm{D}}^{22}=+13.78(c$ 0.3, $\left.\mathrm{H}_{2} \mathrm{O}\right)$, [ref. 4: $\left.[\alpha]_{\mathrm{D}}^{22}=+14.80\left(c 0.3, \mathrm{H}_{2} \mathrm{O}\right)\right]$. IR (ATR) $\nu_{\max }: 3193$; $2917 ; 2880 ; 1422 ; 1333 ; 1112 ; 1022 ; 1000 ; 819 ; 737 ; 635 ; 561$; $416 \mathrm{~cm}^{-1} \cdot{ }^{1} \mathrm{H}$ NMR $\left(600 \mathrm{MHz}, \mathrm{D}_{2} \mathrm{O}, \mathrm{TSP}-d_{4}\right) \delta(\mathrm{ppm}) 1.66$ (ddd, $J$ $\left.=6.9,8.3,13.0 \mathrm{~Hz}, 1 \mathrm{H}, \mathrm{H}-6_{\mathrm{a}}\right), 2.41(\mathrm{dt}, J=6.7,13.0 \mathrm{~Hz}, 1 \mathrm{H}, \mathrm{H}-$ $\left.6_{\mathrm{b}}\right), 2.93(\mathrm{ddd}, J=3.8,6.1,9.1 \mathrm{~Hz}, 1 \mathrm{H}, \mathrm{H}-3), 3.14-3.19(\mathrm{~m}, 1 \mathrm{H}, \mathrm{H}-$ 5), 3.41 (t, $J=4.3 \mathrm{~Hz}, 1 \mathrm{H}, \mathrm{H}-7 \mathrm{a}), 3.57$ (dd, $J=5.4,11.3 \mathrm{~Hz}, 1 \mathrm{H}, \mathrm{H}-$ 9a), $3.66\left(\mathrm{dd}, J=6.1,11.7 \mathrm{~Hz}, 1 \mathrm{H}, \mathrm{H}-8_{\mathrm{a}}\right), 3.68(\mathrm{dd}, J=6.4$, $11.3 \mathrm{~Hz}, 1 \mathrm{H}, \mathrm{H}-9_{\mathrm{b}}$ ), 3.78 (dd, $J=3.8,11.7 \mathrm{~Hz}, 1 \mathrm{H}, \mathrm{H}-8_{\mathrm{b}}$ ), 3.97 (dd,
$J=4.1,9.1 \mathrm{~Hz}, 1 \mathrm{H}, \mathrm{H}-2), 4.16(\mathrm{t}, J=4.0 \mathrm{~Hz}, 1 \mathrm{H}, \mathrm{H}-1), 4.63(\mathrm{td}, J=$ 4.6, $6.9 \mathrm{~Hz}, 1 \mathrm{H}, \mathrm{H}-7) .{ }^{13} \mathrm{C}$ NMR $\left(150 \mathrm{MHz}, \mathrm{D}_{2} \mathrm{O}\right) \delta(\mathrm{ppm}) 40.9$ (C6), 65.6 (C-9), 67.6 (C-8), 71.1 (C-5), 72.1 (C-7), 72.4 (C-3), 73.6 (C1), 76.4 (C-7a), 77.6 (C-2). HRMS (ESI) $m / z$ : for $\mathrm{C}_{9} \mathrm{H}_{18} \mathrm{NO}_{5}[\mathrm{M}+$ $\mathrm{H}]^{+}$, calcd: 220.1180 ; found: 220.1178 .

\section{Cell culture and cultivation conditions}

All the cell passage numbers were lower than 25. Cells were maintained under standard cultivation conditions: $37{ }^{\circ} \mathrm{C}$, humidified atmosphere containing $5 \% \mathrm{CO}_{2}$.

The human glioblastoma astrocytoma cancer cell line U84MG was purchased from ATCC, USA. Cells were cultivated in Dulbecco's Modified Eagle's Medium (DMEM) high glucose supplemented with L-glutamine $2 \mathrm{mM}$, sodium pyruvate $1 \mathrm{mM}$, $1 \%$ non-essential amino acids (NAA) and $10 \%$ fetal bovine serum (FBS).

The HK-2 (purchased from ATCC, USA), an immortalized proximal tubular cell line was cultivated in DMEM high glucose medium supplemented with $2 \mathrm{mM}$ L-glutamine and 10\% FBS.

The hepatocellular carcinoma cell line HepG2 (ECACC, UK) was cultivated in DMEM high glucose medium containing Lglutamine $2 \mathrm{mM}, 10 \%$ FBS, $1 \%$ NAA.

The human placental choriocarcinoma cells JEG-3 (ECACC, UK) were cultivated in Minimum Essential Medium Eagle (MEM) containing 1\% NAA, sodium pyruvate $1 \mathrm{mM}$ and $10 \%$ FBS.

DMEM, MEM and all used supplements were purchased from Sigma-Aldrich, USA except for FBS, which was purchased from Biosera, South America.

\section{Cell viability testing}

All the tested cells were seeded in a 96-well plate (TPP, Switzerland) at low density $4 \times 10^{3}$ cells per well. Cells were treated 24 hours after seeding with medium containing tested substance at indicated concentrations, 1\% DMSO (non-toxic control, $100 \%$ viability) or $10 \%$ DMSO (toxic control, $100 \%$ mortality). Stock solution of tested compounds were prepared by dissolution in DMSO (Sigma-Aldrich, USA) and dilution in cultivation medium to set wanted concentration. Amount of solvent was $1 \%(\mathrm{~V} / \mathrm{V})$ in all cases except toxic control (10\%). The cells were incubated with compounds for 24, 48 and 72 hours, respectively, under standard culture conditions. Viability of cells was determined using CellTiter 96® AQueous One Solution Cell Proliferation Assay (Promega, USA) according to the manufacturer's instructions.

$\mathrm{IC}_{50}$ values were determined using the GraphPad Prism 8.3.1 software.

\section{Conflicts of interest}

There are no conflicts to declare.

\section{Acknowledgements}

This work was supported by the Slovak Grant Agency for Science VEGA (project no. 1/0552/18), and Charles University Research 
Programme Progres (grant no. Q42). The authors are sincerely grateful to Ing. Miroslav Koóš, DrSc. from the Slovak Academy of Sciences for the generous gift of L-mannose which was used as the starting material in the presented total synthesis.

\section{Notes and references}

1 (a) R. J. Nash, in Bioactive Natural Products, ed S. M. Colegate and R. J. Molyneux, CRC Press, Boca Raton, 2nd edn, 2008, pp. 407-420; (b) T. D. Butters, R. A. Dwek and F. M. Platt, Chem. Rev., 2000, 100, 4683; (c) I. Robina, A. J. MorenoVargas, A. T. Carmona and P. Vogel, Curr. Drug Metab., 2004, 5, 329; (d) P.-H. Liang, W.-C. Cheng, Y.-L. Lee, H.-P. Yu, Y.-T. Wu, Y.-L. Lin and C.-H. Wong, ChemBioChem, 2006, 7, 165; (e) V. H. Lillelund, H. H. Jensen, X. F. Liang and M. Bols, Chem. Rev., 2002, 102, 515; $(f)$ E. Borges de Melo, A. da Silva Gomes and I. Carvalho, Tetrahedron, 2006, 62, 10277; $(g)$ S. GerberLemaire and L. Juillerat-Jeanneret, Mini-Rev. Med. Chem., 2006, 6, 1043.

2 (a) N. Asano, R. J. Nash, R. J. Molyneux and G. W. J. Fleet, Tetrahedron: Asymmetry, 2000, 11, 1645; (b) N. Asano, J. Enzyme Inhib., 2000, 15, 215; (c) A. A. Watson, G. W. J. Fleet, N. Asano, R. J. Molyneux and R. J. Nash, Phytochemistry, 2001, 56, 265; (d) R. J. Nash, A. Kato, C.-Y. Yu and G. W. J. Fleet, Future Med. Chem., 2011, 3, 1513.

3 A. Kato, N. Kato, I. Adachi, J. Hollinshead, G. W. J. Fleet, C. Kuriyama, K. Ikeda, N. Asano and R. J. Nash, J. Nat. Prod., 2007, 70, 993.

4 T. Sengoku, Y. Satoh, M. Takahashi and H. Yoda, Tetrahedron Lett., 2009, 50, 4937.

5 (a) A. W. Carroll, A. C. Willis, M. Hoshino, A. Kato and S. G. Pyne, J. Nat. Prod., 2019, 82, 358; (b) A. W. Carroll and S. G. Pyne, Curr. Org. Synth., 2019, 16, 498; (c) T. Ritthiwigrom and S. G. Pyne, Stud. Nat. Prod. Chem., 2012, 36, 1; (d) R. Lahiri, A. A. Ansari and Y. D. Vankar, Chem. Soc. Rev., 2013, 42, 5102; (e) J. Robertson and K. Stevens, Nat. Prod. Rep., 2014, 31, 1721; $(f)$ V. Desvergnes and Y. Landais, Stud. Nat. Prod. Chem., 2014, 42, 373; $(g)$
S. T. Martinez, C. Belouezzane, A. C. Pinto and T. Glasnov, Org. Prep. Proced. Int., 2016, 48, 223; (h) J. Robertson and K. Stevens, Nat. Prod. Rep., 2017, 34, 62.

6 T. Malatinský, B. Otočková, L. Dikošová and R. Fischer, ChemistrySelect, 2019, 4, 4233.

7 O. Tamura, A. Toyao and H. Ishibashi, Synlett, 2002, 1344.

8 (a) A. Peer and A. Vasella, Helv. Chim. Acta, 1999, 82, 1044; (b) S. Desvergnes, S. Py and Y. Vallée, J. Org. Chem., 2005, 70, 1459.

9 (a) T. Malatinský, M. Spišáková, M. Babjak, J. Doháňošová, J. Marek, J. Moncol and R. Fischer, Eur. J. Org. Chem., 2017, 1086; (b) T. Malatinský, Z. Puhová, M. Babjak, J. Doháňošová, J. Moncol, Š. Marchalín and R. Fischer, Tetrahedron Lett., 2018, 59, 3867.

10 E. A. Brock, S. G. Davies, J. A. Lee, P. M. Roberts and J. E. Thomson, Org. Biomol. Chem., 2013, 11, 3187.

11 J. A. Tamayo, F. Franco and F. Sánchez-Cantalejo, Eur. J. Org. Chem., 2011, 7182; and references cited therein.

12 T. S. Cooper, P. Laurent, C. J. Moody and A. K. Takle, Org. Biomol. Chem., 2004, 2, 265.

13 Y. Kondo, N. Suzuki, M. Takahashi, T. Kumamoto, H. Masu and T. Ishikawa, J. Org. Chem., 2012, 77, 7988.

14 K. Inoue, A. Sawada, I. Shibata and A. Baba, J. Am. Chem. Soc., 2002, 124, 906.

15 H. Sun and S. G. DiMagno, J. Am. Chem. Soc., 2005, 127, 2050. 16 M. Jasiński, E. Moreno-Clavijo and H.-U. Reissig, Eur. J. Org. Chem., 2014, 442.

17 (a) W.-J. Liu, J.-L. Ye and P.-Q. Huang, Org. Biomol. Chem., 2010, 8, 2085; (b) M. R. Wormald, R. J. Nash, P. Hrnciar, J. D. White, R. J. Molyneux and G. W. J. Fleet, Tetrahedron: Asymmetry, 1998, 9, 2549; (c) T. J. Donohoe, H. O. Sintim and J. Hollinshead, J. Org. Chem., 2005, 70, 7297; (d) T. J. Donohoe, R. E. Thomas, M. D. Cheeseman, C. L. Rigby, G. Bhalay and I. D. Linney, Org. Lett., 2008, 10, 3615 .

18 H. Fiaux, F. Popowycz, S. Favre, C. Schütz, P. Vogel, S. Gerber-Lemaire and L. Juillerat-Jeanneret, J. Med. Chem., 2005, 48, 4237. 